University of Wollongong

Research Online

Faculty of Engineering and Information

Faculty of Engineering and Information

Sciences - Papers: Part A

Sciences

$1-1-2016$

Bacterial community dynamics in an anoxic-aerobic membrane bioreactor impact on nutrient and trace organic contaminant removal

Hop V. Phan

University of Wollongong, vhp997@uowmail.edu.au

Faisal I. Hai

University of Wollongong, faisal@uow.edu.au

Ren Zhang

University of Wollongong, rzhang@uow.edu.au

Jinguo Kang

University of Wollongong, jkang@uow.edu.au

William E. Price

University of Wollongong, wprice@uow.edu.au

See next page for additional authors

Follow this and additional works at: https://ro.uow.edu.au/eispapers

Part of the Engineering Commons, and the Science and Technology Studies Commons

Research Online is the open access institutional repository for the University of Wollongong. For further information contact the UOW Library: research-pubs@uow.edu.au 


\title{
Bacterial community dynamics in an anoxic-aerobic membrane bioreactor - impact on nutrient and trace organic contaminant removal
}

\author{
Abstract \\ The bacterial community in different redox regimes of an anoxic-aerobic MBR under different operating \\ conditions was investigated using pyrosequencing. With internal recirculation (IR) between the anoxic and \\ aerobic reactors, the bacterial communities in these reactors were highly similar in structure and \\ phylogenetic relationship, indicating IR as a key driving force shaping the bacterial communities that are \\ responsible for the core function in the system. Without IR, each redox condition sustained the growth of \\ distinct bacterial communities according to their oxygen requirement, and the anoxic community \\ presented a low capacity of nutrient and trace organic contaminant (TrOC) removal. Higher bacterial \\ diversity under longer sludge retention time (SRT) was evident; however, except for a few TrOCs, removal \\ efficiency of TOC, TN and TrOCs were the same irrespective of the SRT. The presence of TrOCs induced \\ shifts in bacterial communities, and a correlation between bacterial communities and TrOC \\ transformation was noted. The important candidates for TrOC biotransformation were the taxa within \\ Proteobacteria, particularly Methylophilales and Myxococcales. Other bacterial groups potentially \\ contributing to TrOC biotransformation were those related to nitrogen removal, such as Rhodocyclales \\ and Plantomycetes. In contrast, the detected members of Cytophagaceae (Bacteroidetes) appeared not \\ to contribute to TrOC biotransformation.

\section{Disciplines} \\ Engineering | Science and Technology Studies

\section{Publication Details} \\ Phan, H. V., Hai, F. I., Zhang, R., Kang, J., Price, W. E. \& Nghiem, L. D. (2016). Bacterial community \\ dynamics in an anoxic-aerobic membrane bioreactor - impact on nutrient and trace organic contaminant \\ removal. International Biodeterioration and Biodegradation, 109 61-72.
}

\section{Authors}

Hop V. Phan, Faisal I. Hai, Ren Zhang, Jinguo Kang, William E. Price, and Long D. Nghiem 


\title{
Bacterial Community Dynamics in an Anoxic-Aerobic Membrane Bioreactor - Impact on Nutrient and Trace Organic Contaminant Removal
}

\author{
Revised manuscript submitted to \\ International Biodeterioration \& Biodegradation \\ Jan, 2016
}

Hop V. Phan ${ }^{\mathrm{a}}$, Faisal I. Hai ${ }^{\mathrm{a} *}$, Ren Zhang ${ }^{\mathrm{b}}$, Jinguo Kang ${ }^{\mathrm{a}, \mathrm{c}}$, William E. Price ${ }^{\mathrm{c}}$, Long D. Nghiem $^{\text {a }}$

${ }^{a}$ Strategic Water Infrastructure Lab, School of Civil, Mining and Environmental Engineering, University of Wollongong, NSW 2522, Australia.

${ }^{\mathrm{b}}$ Molecular Biology Lab, School of Biological Sciences, University of Wollongong, NSW 2522, Australia.

'Strategic Water Infrastructure Lab, School of Chemistry, University of Wollongong, NSW 2522, Australia.

*Corresponding author: Faisal I. Hai (E-mail: faisal@uow.edu.au; Phone: +61-2-4221-3054) 


\begin{abstract}
The bacterial community in different redox regimes of an anoxic-aerobic MBR under different operating conditions was investigated using pyrosequencing. With internal recirculation (IR) between the anoxic and aerobic reactors, the bacterial communities in these reactors were highly similar in structure and phylogenetic relationship, indicating IR as a key driving force shaping the bacterial communities that are responsible for the core function in the system. Without IR, each redox condition sustained the growth of distinct bacterial communities according to their oxygen requirement, and the anoxic community presented a low capacity of nutrient and trace organic contaminant (TrOC) removal. Higher bacterial diversity under longer sludge retention time (SRT) was evident; however, except for a few TrOCs, removal efficiency of TOC, TN and TrOCs were the same irrespective of the SRT. The presence of TrOCs induced shifts in bacterial communities, and a correlation between bacterial communities and TrOC transformation was noted. The important candidates for TrOC biotransformation were the taxa within Proteobacteria, particularly Methylophilales and Myxococcales. Other bacterial groups potentially contributing to TrOC biotransformation were those related to nitrogen removal, such as Rhodocyclales and Plantomycetes. In contrast, the detected members of Cytophagaceae (Bacteroidetes) appeared not to contribute to TrOC biotransformation.
\end{abstract}

Keywords: Bacterial community; Internal recirculation; Membrane bioreactor; Trace organic contaminant; Redox condition; and Nutrient removal. 
Biological wastewater treatment efficiency is governed by the composition and function of microbial communities, but it is still not clear which selective factors shape these communities in anoxic-aerobic membrane bioreactors (MBRs). The combination of anoxic and aerobic reactors and internal recirculation (IR) between these reactors potentially creates a unique niche for the development of a shared bacterial community. It has been suggested that higher the IR, more similar the bacterial communities in anoxic and aerobic bioreactors is (Xia et al., 2012; GómezSilván et al., 2014). Nitrifying and denitrifying bacteria were found to be active in both redox conditions in such cases (Gómez-Silván et al., 2014). Possibly, the bacterial communities that grow in this combined system are facultative, but this is yet to be systematically verified.

Trace organic contaminants (TrOCs) are frequently detected in raw and insufficiently treated wastewater as well as wastewater-impacted natural water bodies (Luo et al., 2014). Recent studies have been devoted to evaluating and improving MBR performance as a barrier to resistant TrOCs (Tadkaew et al., 2011). Long SRT and high MLSS concentration in MBRs can be advantageous for TrOC biotransformation (Xia et al., 2012). Furthermore, the combination of different redox conditions (anoxic and aerobic) in anoxic-aerobic MBRs creates a biologically active environment that can enhance biodegradation of some TrOCs (Stadler et al., 2015). TrOC biotransformation capacity was suggested to significantly depend on the bacterial composition in sludge (Boonnorat et al., 2014). However, information related to bacterial groups responsible for TrOC biodegradation in activated sludge remains scarce.

The diversity and low concentration (as low as a few ng/L) of TrOCs in environment are challenges for identifying functional bacterial groups of TrOC biodegradation. A few recent studies have indirectly shown a relationship between TrOC biotransformation and nitrification (Helbling et al., 2012; Tran et al., 2013) although it has also been suggested that both heterotrophic and autotrophic bacteria are responsible for TrOC biotransformation. Thayanukul et al. (2010) reported that different bacterial groups may be responsible for biotransformation at different TrOC concentrations. Controversies related to the impact of TrOCs on bacterial community development also exist in the literature. For example, while TrOCs were found to affect oxygen uptake rate of bacterial population, removal of carbon and nitrogen was within the range of stable performance i.e., more than 90\% and 93\% removal of COD and TN, respectively (Navaratna et al., 2012). On the other hand, a few other studies indicate the need for an acclimatization period before a stable TrOC removal performance or microbial community can be obtained (Alidina et al. 2014; Boonnorat et al. 2014). Thus more systematic studies are required to elucidate the functional bacterial groups for TrOC biodegradation and the impact of TrOCs on microbial community composition.

Given the research gaps discussed above, the current study employs pyrosequencing technique to profile the bacterial communities developed in different redox regimes of an anoxic-aerobic MBR system with and without internal recirculation between the anoxic and the aerobic reactors. The results provide insights into the impact of TrOC addition on the bacterial communities. The potential impact of the operating SRT on bacterial communities and the removal performance is also discussed. Systematic monitoring of the shift of bacterial communities under the changes of individual operating parameters combined with removal performance data over long-term period assists in shedding light on the functional bacterial groups in the anoxic-aerobic MBR system treating nutrients and TrOCs. 


\subsection{Anoxic-aerobic membrane bioreactor design and operation}

The laboratory scale anoxic-aerobic MBR comprised an anoxic (14 l) and an aerobic (12 l) bioreactor. Details of the reactor set-up and operation protocol has been described in Supplementary data Figure S1. Briefly, a hollow fibre ultrafiltration membrane (Zeweed-10) supplied by Zenon Environmental (Ontario, Canada) was immersed in the aerobic reactor. A certain volume of the mixed liquor was constantly recirculated from the aerobic to the anoxic reactor. The ratio of the mixed liquor recirculation flow rate to the feed flow rate was denoted as internal recirculation (IR) ratio.

The MBR system was initially seeded with activated sludge from the biological nutrient removal unit of the Wollongong Sewage Treatment Plant (Wollongong, Australia). It was operated for $305 \mathrm{~d}$ with a total hydraulic retention time (HRT) of $24 \mathrm{~h}$ (i.e., $13 \mathrm{~h}$ in the anoxic tank and $11 \mathrm{~h}$ in the aerobic tank). The mixed liquor $\mathrm{pH}$ was stable at $7.25 \pm 0.75$. Dissolved oxygen concentration (DO) was maintained at above $3 \mathrm{mg} \mathrm{l}^{-1}$ (aerobic reactor) and approximately $0.1 \mathrm{mg} \mathrm{l}^{-1}$ (anoxic reactor). The oxidation reduction potential (ORP) of the aerobic reactor remained relatively stable at $141 \pm$ $18 \mathrm{mV}$. In the anoxic reactor, the ORP varied in the range of $-122 \pm 22 \mathrm{mV}(\mathrm{n}=40)$ and $-230 \pm 75$ $\mathrm{mV}(\mathrm{n}=15)$ with and without IR, respectively. During operation without sludge withdrawal, although the MLSS concentration increased for both reactors, MLVSS/MLSS ratios were stable at $0.71 \pm 0.02$ and $0.70 \pm 0.01$ for the anoxic and aerobic reactors, respectively. Under an SRT of $25 \mathrm{~d}$, MLVSS/MLSS ratios were $0.78 \pm 0.07$ and $0.73 \pm 0.05$ for the anoxic and aerobic reactors, respectively.

The system was fed by synthetic wastewater prepared daily (Phan et al., 2014). A set of 30 compounds representing five major groups of TrOCs, namely pharmaceuticals and personal care products, pesticides, steroid hormones, industrial chemicals, and phytoestrogens were used in this study (Supplementary data Table S2). These TrOCs were selected based on their widespread occurrence in domestic sewage and their diverse physicochemical properties (Phan et al., 2014). A combined stock solution of TrOCs was prepared in pure methanol and stored at $-20{ }^{\circ} \mathrm{C}$ in the dark. To assess the MBR performance under TrOC dosing, TrOCs were continuously added to the synthetic wastewater at a final concentration of $5 \mathrm{\mu g} \mathrm{l}^{-1}$ of each selected compound.

After a start-up period of 125 d (i.e., sludge acclimatization and stabilization of TOC/TN removal), the MBR was run under four main operational regimes to evaluate the MBR performance and to determine the role of IR and redox conditions on the nutrient and TrOC removal by the system. Briefly, the MBR was first operated without sludge wastage ('infinite' SRT) and with an IR of 3 in presence of TrOC in the influent for $55 \mathrm{~d}$ (Days 126-170). This run was conducted to establish a baseline. The SRT of the MBR was changed to $25 \mathrm{~d}$ for the rest of the investigation period. At the beginning of the operation under an SRT of $25 \mathrm{~d}$, the MBR system was operated for a period of 55 $\mathrm{d}$ without any addition of TrOCs to the synthetic wastewater. This run was conducted to ensure stable biological performance in term of TOC and TN removal following the change in SRT. TrOC spiking to the synthetic wastewater was resumed from Day 226. The MBR was then run for $40 \mathrm{~d}$ at an IR ratio of 3 . The MBR was operated for a further $35 \mathrm{~d}$ without IR to assess the impact of recirculation of media from the aerobic to the anoxic reactor.

\subsection{Analytical methods}

\subsubsection{Basic parameters and TrOC analysis}

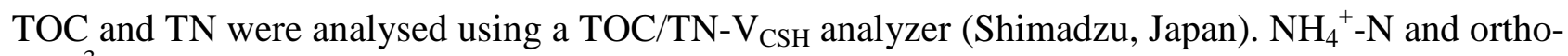
$\mathrm{PO}_{4}^{-3}-\mathrm{P}$ concentrations were measured using flow injection analysis (Lachat instruments, Milwaukee, USA) following the Standard Methods 4500- $\mathrm{NH}_{3} \mathrm{H}$ and 4500-P G, respectively (Eaton 
et al., 2005). Ion Chromatography (IonPac AS23 Anion-Exchange Column, Dionex Corporation, USA) was applied to quantify anions such as nitrate and nitrite. MLSS and MLVSS concentrations in bioreactors were measured according to the Standard Method 2540 (Eaton et al., 2005).

The concentration of the selected TrOCs in the feed and supernatant of the anoxic bioreactor and the aerobic MBR permeate was determined using a gas chromatography-mass spectrometry (GCMS) method described by Hai et al. (2011). TrOCs in sludge were extracted by a previously developed solvent extraction method (Wijekoon et al., 2013) prior to GC-MS analysis.

\subsubsection{Activated sludge sampling, DNA extraction and Pyrosequencing}

Activated sludge samples for analysis of bacterial communities were collected from both anoxic and aerobic bioreactors at the end of each operational regime i.e., on Day 152, 225, 265 and 304 as shown in Table 1 . The sludge samples were immediately frozen at $-20{ }^{\circ} \mathrm{C}$ for later processing or pelleted immediately by centrifugation at $10,000 \mathrm{x}$ g for 10 minutes. DNA extraction was carried out using the FastDNA spin kit for soil (MP Biomedical, Australia) following the manufacturer's protocol. The genomic DNA extract was analysed to determine its integrity, purity and concentration using $1 \%$ electrophoresis agarose gel and Nanodrop ${ }^{\circledR}$ ND-1000 spectrophotometer.

[Table 1]

454 pyrosequencing of the extracted DNA were conducted by the Australian Genome Research Facility. Amplicon pyrosequencing was performed using a standard Roche 454/GS-FLX Platform. The Bacterial domain was targeted by selecting the V1-V3 regions of the 16S rRNA gene with the forward primer 27F (5'- AGAGTTTGATCMTGGCTCAG- 3') and the reverse primer 519R (5'GWATTACCGCGGCKGCTG- 3'). The 16S rRNA sequences have been deposited in NCBISequence Read Archive (accession number SRP062401).

\subsubsection{Sequence analysis}

SSU rRNA gene amplicons generated from pyrosequencing were processed using the Quantitative Insights Into Microbial Ecology (QIIME v1.8.0) software package (Caporaso et al., 2010b). Sequences were binned by barcode and quality filtered using the "split_libararies.py" script. Sequences were discarded if containing ambiguous bases, errors in the barcode or primer, a length outside of $200-600 \mathrm{nt}$, minimum average quality score less than 25, and homopolymers greater than 6 nt. The remaining sequences was denoised by "denoised_wrapper.py" script and then subjected to the following procedures using QIIME scripts: (1) operational taxonomic units (OTUs) were assigned (at $97 \%$ similarity) by uclust (Edgar, 2010) ; (2) the cluster centroid for each OTU was selected as representative sequence that was taxonomically classified based on GreenGenes using uclust (Edgar, 2010); (4) the cluster representatives were aligned against a template alignment of the GreenGenes database using PyNast (Caporaso et al., 2010a), and the gaps and excessive variable regions were filtered; (5) Phylogenetic tree was generated using FastTtree. After removing Chimeric sequences using ChimeraSlayer, a total of 33,116 high quality amplicon reads were obtained with sequence statistics of 1946/5728/4014/1318 (min/max/median/std.dev., respectively). A total of 3422 OTUs at a $97 \%$ sequence similarity cut-off level were observed.

In order to eliminate heterogeneity related to different numbers of sequences among the samples, both $\alpha$ - and $\beta$-diversity metrics were estimated with even subsampling at 1,900 sequences per sample (the lowest number of sequences among the samples). Specifically, $\alpha$-diversity metrics included Chao1, Shannon index and phylogenetic diversity. Good's coverage was used to estimate the sampling completeness and estimate the probability that a randomly selected amplicon sequence from a sample has already been sequenced. $\beta$-diversity estimates were calculated within QIIME using both unweighted and weighted UniFrac distances (Lozupone and Knight, 2005). The UniFrac distance metrics were interpreted to compare all communities simultaneously using standard 
multivariate statistical methods: a hierarchical clustering method (unweighted pair group method with arithmetic averages, UPGMA) and principal coordinate analysis (PCoA).

\section{Results and discussion}

The integrated anoxic-aerobic MBR was initially operated with no sludge withdrawal (infinite SRT) as a reference, and then under an SRT of $25 \mathrm{~d}$ for the rest of the operation period. The changes in operating conditions, namely SRT (infinite vs. 25 d), presence/absence of TrOC in influent, and application of IR affected the bulk organics, nutrient and TrOC removal performance. The changes in bacterial communities and their functions due to changes in operating conditions have been discussed in Section 3.2 and 3.3, while the correlation between system performance and changes in bacterial communities is discussed in Section 3.4.

\subsection{Removal performance}

The removal efficiency of bulk organic and nutrient is summarized in Table 2The MBR achieved high (approximately 99\%) and stable overall TOC removal throughout the entire operation period. Similarly, effluent ammonia was below detection limit regardless of changes in SRT, the presence/absence of TrOC in the influent, and IR. Conversely, the removal of TN and orthophosphate depended on IR: over 80 and over 90\% removal of TN and orthophosphate, respectively, was achieved with an IR ratio of 3 (Condition 1, 2 and 3), which declined significantly when IR was ceased (Condition 4).

[Table 2]

The introduction of 30 selected TrOCs to the feed wastewater did not have a discernible impact on the basic biological performance of the MBR including TOC and TN (Table 2). More than 90\% removal was observed for 21 of the 30 added TrOCs (Table 3). In general, a similar TrOC removal performance was noted irrespective of the SRT i.e., during application of infinite SRT (Condition 1) and an SRT of 25d (Condition 3), except for two recalcitrant compounds (carbamazepine and gemfibrozil) that were better removed during the longer SRT operation (Table 3) (Phan et al., 2014).

\section{[Table 3]}

When IR was used, due to the well mixed conditions, virtually no difference between the removal performance of the anoxic and aerobic reactors was noted. However, operation without any IR between the bioreactors provided a clearer indication of the TrOC removal capacity of the anoxic reactor. In the absence of IR, nine TrOCs, namely, primidone, metronidazole, triclosan, amitriptyline, 17ß-estradiol-17-acetate, 4-tert-octylphenol, benzophenone, oxybenzone and octocrylene were removed with efficiencies ranging $50-90 \%$ by the anoxic bioreactor (Supplementary data Table S3). Among these, however, triclosan, amitriptyline, 4-tert-octylphenol, benzophenol and octocrylene were removed mainly via adsorption to the sludge (Data not shown), suggesting a low TrOC transformation capacity by anoxic sludge in absence of IR (Condition 4). Despite the variation in TrOC concentration in the anoxic reactor (depending on IR), the TrOC in the effluent of the subsequent aerobic MBR remained stable, indicating a major contribution of TrOC biodegradation by the aerobic reactor to the overall removal achieved by the anoxic-aerobic MBR (Supplementary data Table S3).

\subsection{Impact of operating conditions on bacterial diversity and structure}

\subsection{1 $\alpha$-diversity}

To verify the changes in the diversity of bacterial communities under different operational conditions in the MBR, the $\alpha$-diversity (diversity within a given community at a local scale) was 
characterized using a qualitative species-based measure (i.e., Chao1 index), quantitative speciesbased measure (i.e., Shannon index) and a qualitative divergence-based measure (PD_whole_tree/phylogenetic distance). Additionally, Good's coverage estimate was used to assess the sampling completeness and estimate the probability that a randomly selected amplicon sequence from a sample has already been sequenced. To eliminate the possible bias due to variation of sequencing depth, $\alpha$-diversity indices were measured and compared at an even sequencing depth of 1900 sequences per sample. Notably, this was the lowest number of sequences per sample noted among the samples (Ttable 4), but the rarefaction curves (Supplementary Data Figure S4) confirmed that the chosen sequencing depth was adequate to present the trend of diversity.

Under an IR of 3, the diversity of bacterial communities (as indicated by Chao1, Observed species, PD_whole_tree and Shannon index) was not significantly different between the anoxic and aerobic bioreactors for each condition (i.e., conditions 1, 2 and 3). Activated sludge samples in Condition 1 (samples Anoxic 152 and Oxic $_{152}$ at infinite SRT) showed the highest diversity (Table 4). Previous studies with SRT within the range of 3 to $60 \mathrm{~d}$ reported higher diversity of bacterial communities under longer SRTs (Xia et al., 2012; Vuono et al., 2015). While consistent with that in previous studies, the results in the current study extend the understanding to the case of no sludge withdrawal (i.e., infinite SRT). Notably, the bacterial diversity between the anoxic and aerobic communities was more similar for samples representing Conditions 1 and 3 (TrOC addition) than Condition 2 (no TrOC addition) (Table 4), indicating the effect of TrOC addition on the development of bacterial community.

The cessation of recirculation between the anoxic and aerobic bioreactors (i.e., $\mathrm{IR}=0$, in Condition 4) resulted in the formation of two distinct communities in the respective bioreactors, as evidenced by the significantly different $\alpha$-diversity indices for the samples Anoxic 304 and Oxic 304 . All $\alpha$ diversity indices (i.e., Chao1, Observed_species; PD_whole_tree; and Shannon index) demonstrated a significantly higher diversity of the aerobic community than that of the anoxic community in Condition 4 (Table 4). Without recirculation, the anoxic bioreactor sample (Anoxic ${ }_{304}$ ) showed an uneven distribution of bacterial community, (i.e, low Shannon index), indicating the dominance of a few bacterial groups.

\subsection{2 $\beta$-diversity}

$\beta$-diversity indicates the partitioning of microbial diversity among environments or along a gradient (e.g., the number of species shared between two environments) (Lozupone et al., 2007). In order to identify the impact of different operational factors (i.e., SRT, TrOC, IR and redox conditions) on the microbial community in the integrated anoxic-aerobic MBR system, the community $\beta$-diversity was measured using both unweighted and weighted UniFrac. It is worth reiterating that unweighted UniFrac is a qualitative measurement based on the presence/absence of bacterial phylotypes, while weighted UniFrac is a quantitative measurement based on the abundance of each bacterial phylotype. The UniFrac distance metrics were interpreted to compare all communities simultaneously using standard multivariate statistical methods (Lozupone et al., 2007), namely, a hierarchical clustering method called Unweighted Pair Group Method with Arithmetic Averages (UPGMA) (Figure 1A and B) and Principal Coordinate Analysis (PCoA) (Figure 1C and D).

UPGMA of both unweighted and weighted UniFrac grouped anoxic and aerobic samples in one cluster for all samples (i.e., Conditions 1, 2 and 3) under a IR ratio of 3 (Figure 1A and B). Data for the anoxic and aerobic samples representing these conditions were positioned closely in the PCoA plot (Figure 1C and D), suggesting that the bacterial communities developed in the aerobic and anoxic reactors in presence of IR were highly similar in composition, structure and phylogenetic relationship. Previous studies also found no significant difference in bacterial communities between different redox regimes of the combined anoxic-aerobic systems in presence of IR (Xia et al., 2012; 
Gómez-Silván et al., 2014). IR from aerobic to anoxic bioreactor may lead to the following (Phan et al., 2014): (i) dilution of the media, (ii) improved mixing/mass transfer, (iii) supply of nitrate, and (iv) transfer of a portion of DO from aerobic tank. Possibly such sludge recirculation leads to the formation of a distinct ecology that facilitates the development of particular bacterial lineages. Gómez-Silván et al. (2014) observed that bacterial populations in an anoxic-aerobic MBR system including ammonia oxidizing bacteria (AOB), nitrite oxidizing bacteria (NOB) and denitrifiers were active under both anoxic and aerobic conditions.

Cessation of IR (Condition 4) led to the formation of two separate redox zones (anoxic vs. aerobic). Accordingly, bacterial communities in anoxic (Anoxic 304 ) and aerobic (Oxic 304 ) samples were distantly clustered into two separate branches of the UPGMA tree (Figure 1A and B) and also plotted distantly from each other in PCoA (Figure 1C and D). It is likely that the separate redox zones (in absence of IR) sustained the growth of specific bacterial lineages according to their oxygen requirement (further discussed in Section 3.3). These observations suggest that IR is a key driving force for the development of bacterial communities in the integrated anoxic-aerobic MBR system.

In addition to IR, the impacts of SRT and TrOC addition were evident via both unweighted and weighted UniFrac analyses, although the order of importance of the factors according to each analysis appeared to be somewhat different. In unweighted UniFrac analysis, the cluster of samples belonging to IR of 3 was perfectly grouped into two distinct clusters according to the SRT (infinite vs. $25 \mathrm{~d}$ ), and then according to TrOC (Figure 1A and C). By contrast, weighted UniFrac clustered the bacterial communities principally by capacity of TrOC biotransformation (Figure 1C and D).

\subsection{Shifts in taxonomic profile}

A total of 26 phyla were assigned to the sequence reads of the eight samples analyzed (Figure 2 and Supplementary Data Table S5). High proportions of unclassified sequences in studies applying pyrosequencing have been previously reported (Zhang et al., 2012). In this study, depending on the sample, the proportions of the unclassified sequences were $4-15 \%, 7-23 \%$ and around $80 \%$ at the phylum, order and genus level, respectively.

Proteobacteria and Bacteroidetes were observed to be the two dominant phyla in all conditions with a relative abundance of $22.8-64.1 \%$ and $14.7-47.7 \%$, respectively (Figure 2). This observation is consistent with their previously reported abundance in activated sludge in general (Zhang et al., 2012; Luo et al., 2016). Based on the presence/absence of each taxon, the diversity analysis presented IR as the key driving force shaping the microbial communities in the integrated anoxic-aerobic MBR, while based on abundance of each bacterial phylotype, the correlation of bacterial communities with TrOC biotransformation capacity was evident (Figure 1). Taxonomic breakdown data (Figure 2, Figure 3 and Figure 4) confirmed the difference in bacterial communities between different conditions (i.e., Conditions 1, 2, 3 and 4) and illustrated the impact of the operating parameters (i.e., SRT, TrOCs and IR). Consistent with the $\alpha$ - (Table 4) and $\beta$ - diversity (Figure 1) indices, the similarity of bacterial communities between the anoxic and aerobic bioreactors in all conditions in presence of IR was also clearly demonstrated by the taxonomic data right from the phylum level (Figure 2) up to the genus level (Figure 3 and Figure 4).

[Figure 2]

\subsubsection{Impact of SRT}

SRT relates to the specific biomass growth rate. Only the microorganisms that have doubling times less than the SRT will grow fast enough to avoid wash out from the system (Vuono et al., 2015). $r$ - 
$K$ selection theory is based on, in addition to maximum growth rate, resource-use efficiency: $K$ strategists that are capable of efficiently utilizing scarce resources will enjoy advantages under long SRT conditions, while $r$-strategists (fast-growing organisms) are adapted for 'high resource' environment under short SRT conditions (Vuono et al., 2015).

In the current study, switching operation from infinite SRT (Condition 1) to an SRT of $25 \mathrm{~d}$ (Conditions 2 and 3) led to the disappearance or great reduction in the relative abundance of many bacterial phylotypes (Figure 2 and Figure 3). A significant reduction in relative abundance was clearly observed at the phylum level for Plantomycetes, Chlorofloxi, Acidobacteria, Nitrospirae and Armatimonadetes (Figure 2). These bacterial phyla (except Armatimonadetes) were previously found to significantly decrease in proportion when SRT was reduced from $30 \mathrm{~d}$ to $12 \mathrm{~d}$ and then to 3 d (Vuono et al., 2015).

In order to have more detailed information, the relative abundance of the bacterial phylotypes at deeper levels of classification was scrutinized (Figure 3). Switching operation from infinite SRT to an SRT of $25 \mathrm{~d}$ led to a significant reduction in relative abundance of the taxa affiliated with Rhodocyclaceae (from $7.3 \pm 1.5 \%, n=2$ to $2.8 \pm 0.9 \%, n=4$ ), Phycisphaerales (from $5.3 \pm 0.2, n$ $=2$ to $0.9 \pm 0.4 \%, n=4)$, Saprospirales $(3.0 \pm 0.1 \%, n=2$ to $0.1 \pm 0.1 \%, n=4)$ and Oxalobacteraceae (Burkholderiales) (from $2.3 \pm 0.0 \%, n=2$ to $0.8 \pm 0.2, n=4$ ) (Figure 3 ). The proportion of Nitrospira (an NOB) was found to significantly decrease from $2.8 \pm 0.5 \%(n=2$, Condition 1: infinite SRT) to $0.5 \pm 0.2 \%(n=4$, Condition 2 and 3: SRT of $25 \mathrm{~d})$. This can be explained by the fact that Nitrospira is a K-strategist that shows dominance at longer SRT (Vuono et al., 2015). The implication of these changes on removal performance will be discussed in Section 3.4.1.

In contrast to the aforementioned examples, a number of taxa were found at higher relative abundance at an SRT of 25d (Conditions 2 and 3) than at infinite SRT (Condition 1) (Figure 3). For example, the relative abundance of 'Candidatus Accumulibacter' (Rhodocyclales) increased from $1.9 \pm 0.0 \%(n=2)$ to $5.8 \pm 0.8 \%(n=4)$ when the SRT was reduced. This increase probably relates to the function of this group - it is known as the most important polyphosphate accumulating organism (PAO) in activated sludge (Nielsen and Seviour, 2010), which requires periodic sludge withdrawal for phosphorous removal. Vuono et al. (2015), also observed an increase in relative abundance of the taxa under the order Rhodocyclales following a decrease in SRT. In the current study, Acinetobacter (Pseudomonadales), another PAO, was also found at higher relative abundance at an SRT of $25 \mathrm{~d}(2.4 \pm 0.6 \%, n=4$ vs. $1.1 \pm 0.3 \%, n=2$, infinite SRT). The implications of the relative abundance of the PAOs on the phosphorous removal performance have been further discussed in Section 3.4.1.

\subsubsection{Impact of TrOC addition}

Weighted UniFrac analysis (Figure 1C and D) categorized the bacterial communities into two distinct clusters: i) communities detected in samples representing periods of effective TrOC biotransformation in both reactors (Conditions 1 and 3) and those representing the aerobic reactor in the absence of IR (Condition 4), and ii) communities present in samples when no TrOC was added (Condition 2) or when reduced TrOC biotransformation was observed (in the anoxic reactor in absence of IR, Condition 4). This pattern was also observed in the taxonomic profiles at phylum level (Figure 2).

Proteobacteria was the most abundant phylum $(51.4 \pm 12.9 \%, n=5)$ in sludge during effective TrOC transformation period (Condition 1, 3 and aerobic sludge in condition 4). By contrast, Bacteroidetes was found to be the most abundant phylum in sludge with low TrOC transformation (anoxic sludge in Condition 4) or in absence of TrOC (Condition 2) (Figure 2). Higher relative 
abundance of Plantomycetes and Chloroflexi was noted in the presence of TrOC in influent, while TM7 was detected in greater proportions in absence of TrOCs (Figure 2).

The relative abundance of the bacterial phylotypes at deeper levels of classification (Figure 3) was in line with the trend observed at the phylum level (Figure 2). Considering the bacterial groups with at least $0.5 \%$ relative abundance, 7 phylotypes were found to occur only when the influent contained TrOC. An additional 11 phylotypes were more abundant in presence of TrOC. Conversely, 6 phylotypes showed higher abundance in absence of TrOC (Figure 3 and Supplementary data Table S6).

The most abundant bacterial phylotypes in sludge samples from the period of effective TrOC removal (Condition 3) was affiliated with Methylophilaceae which showed a relative abundance of $32.5 \%$ and $29.4 \%$ in anoxic and aerobic samples, respectively (Figure 3). However, it was absent in samples collected during Condition 2 with the same SRT of $25 \mathrm{~d}$ and the IR ratio of 3, but without TrOC in influent. Without IR (Condition 4), this group showed higher relative abundance in aerobic sludge (6.6\%) than in the anoxic sludge (3.9\%) (Figure 4). These observations indicate that Methylophilaceae is a potential candidate for TrOC metabolism as discussed further in Section 3.4.

Bacterial phylotypes associated with Plantomyces (Plantomycetales), Gemmataceae (Gemmatales), Caldilinea (Caldilineales) and Lactococcus (Lactobacillales) showed relative abundance of 1 - $2 \%$ during periods when IR was applied and effective TrOC removal was achieved (Condition 3 and/or Condition 1), while they showed very low relative abundance in Condition $2(0.1-0.4 \%)$. In the absence of IR (Condition 4), these bacterial phylotypes mostly disappeared or occurred at very low relative abundances $(<0.3 \%)$ (Supplementary data Table S6). When detected, these bacterial lineages comprised a small portion of the whole community, but it is likely that they contributed to TrOC degradation. For example, many genera in Lactobacillales are thought to include species resistant to a broad range of antibiotic (Lactobacillus, Enterococcus, Streptococcus, Leuconostoc and Pediococcus) or capable of converting estrogens (Streptococcus) (Rabia and Shah, 2011). Gemmatales and Planctomycetales (Plantomycetes) have been reported to be involved in degradation of aromatic compounds including ethylbenzene, aminobenzene, naphthalene, bisphenol A, chloroxyclohexane, and polycyclic aromatic hydrocarbon (Guo et al., 2014).

In line with the observations at the phylum level (Figure 2), bacterial phylotypes associated with Cytophagaceae (Cytophagales) formed the most abundant group $(34.1 \pm 4.2 \%, n=3)$ in aerobic/anoxic sludge without TrOC addition (Condition 2) or in anoxic sludge showing low effective TrOC transformation in absence of IR (Condition 4). However, they only accounted for 7 $-12 \%$ in sludge showing effective TrOC transformation capacity (Conditions 1, 2 and aerobic sludge in Condition 4) (Figure 3 and Figure 4). A previous study using microautoradiographyfluorescene hybridization (Zang et al., 2008) found no estrogen-assimilating cells affiliated with the Cytophaga-Flavobacterium cluster. This cluster was also reported not to bear pharmaceuticals or striazines degradation capacity (Caracciolo et al., 2010). Possibly TrOC addition and their transformation products induced inhibition on the growth of these bacterial phylotypes.

Members belonging to the order Myxococcales were found at similar relative abundance (4.6 6.1\%) in all three Conditions (i.e., 1, 2 and 3), meaning that the factors SRT or TrOCs did not exert noticeable impact on their growth (Figure 3). However, their abundance was significantly changed by stopping IR in Condition 4 as discussed in the next section.

\subsubsection{Impact of IR}

IR between anoxic and aerobic reactors possibly formed an environment that facilitated the development of a particular bacterial community shared between these two redox regimes. This shared community may be responsible for the core function of the integrated anoxic-aerobic MBR 
system. Taxonomic profile reveals that without IR, anoxic and aerobic reactors developed unique bacterial communities distinct from the shared communities formed under an IR of 3.

Stopping recirculation led to the disappearance or significant reduction in relative abundance of many bacterial phylotypes that were abundant in Condition 3 (i.e., SRT $=25 \mathrm{~d}, \mathrm{IR}=3$, TrOC in influent). Significant changes in bacterial communities were evident at phylum level (Figure 2 and Supplementary data Table S5). As discussed in Section 3.3.2, bacterial phylotype affiliated with Methylophilaceae was the most predominant group under Condition $3(31.0 \pm 2.2 \%, n=2)$. In absence of IR (Condition 4), its abundance decreased significantly to 3.8 and $6.0 \%$ for anoxic and aerobic samples, respectively (Figure 4). "Candidatus Accumulibacter" (Rhodocyclales), a key PAO, was one of the most predominant genus detected in Condition $3(6-7 \%)$, but this bacterial phylotype almost disappeared in Condition $4(0.4 \%$ and $0.1 \%$ for anoxic and aerobic sludge, respectively) (Figure 4). This may be explained by the fact that PAOs rely on alternative anoxic/aerobic regimes to accumulate phosphate and produce energy for growth. The members of the orders Rhizobiales, Methylophilales, Rhodocyclales are known to have denitrifying capacity (Nielsen and Seviour, 2010). Therefore, their appearance in reduced proportions was probably the result of stopping recirculation that controlled the supply of nitrate from the aerobic zone to the anoxic zone.

Some bacterial phylotypes were enriched only in the anoxic reactor in absence of IR (Condition 4). The most abundant bacterial phylotype in anoxic sludge in Condition 4 was affiliated with Cytophagaceae (37.6\%), which, however, comprised only $7-9 \%$ of the anoxic/aerobic community in Condition 3 or aerobic community in Condition 4 (Figure 4). Their abundance can be explained by their capacity of consuming low- and high- molecular weight dissolved organic matter (Cottrell and Kirchman, 2000), which possibly gained them an advantage in competition with other organisms in the anoxic zone (where influent enters first) under Condition 4.

The removal performance of the aerobic reactor was similar in all four conditions. However, the aerobic sludge in Condition 4 (without IR) supported the growth of a unique bacterial community. The most dominant bacterial phylotype at this stage was affiliated with Myxococcales, which accounted for more than $32 \%$ of the community. This bacterial group comprised only around $5 \%$ of the community detected in aerobic/anoxic samples in Condition 3 (with IR), and a very low proportion (0.2\%) of that in the anoxic sludge of Condition 4 (Figure 4), clearly demonstrating the impact of internal recirculation between anoxic/aerobic reactors on this group. Notably, Myxobacteria are predominantly found in aerobic habitats and are capable of excreting hydrolytic enzymes and decomposing various complex biopolymers (Garrity et al., 2006). Another notable example is Flavobacterium, which showed a relative abundance of 3.8\% in the aerobic sludge when IR was ceased, but this genus was not found during operation with IR, suggesting that this group may prefer strictly aerobic environment. Pentachlorophenol degradation by an aerobic, chlorophenol-utilizing Flavobacterium sp. has been reported (Steiert and Crawford, 1986). Phylotypes affiliated with Rhizobiales, Comamonadaceae (Burkholderiales) and Pedosphaerales showed significantly higher relative abundance $(2-5 \% v s$. $<0.8 \%)$ in aerobic sludge in absence of IR. As discussed in Section 3.4, members of Rhizobiales and Burkhoderiales are capable of utilizing TrOCs.

The differences in the bacterial communities developed under conditions with/without IR not only explain the variations in the nutrient removal performance by the system (Table 2), but also provide insights into the variation in TrOC biodegradation and sorption under different redox conditions as described in the following sections.

[Figure 4] 


\subsubsection{Bulk organic and nutrient removal}

414 Changes in the structure of bacterial communities in anoxic and aerobic samples between 415 Conditions 1, 2 and 3 were noticed in response to changes in SRT or addition of TrOC in influent. However, the bulk organic and nutrient removal efficiency remained virtually unchanged. A high and stable overall TOC removal was achieved throughout the operation period (Table 2). Complete nitrification and over $80 \%$ TN removal was consistently achieved in all three conditions with an IR ratio of 3 . During operation with IR, more than $90 \%$ phosphate removal was maintained, although the system was not designed specifically for phosphate removal (e.g., there was no strictly anaerobic reactor). A possible explanation for this stable removal of TOC and TN despite the changes in relative abundance of the bacterial phylotypes is the functional redundancy of microbial community in activated sludge i.e., the presence of a pool of species able to perform the same ecological function (Briones and Raskin, 2003). Possibly, an SRT of $25 \mathrm{~d}$ was adequate to sustain the development of functional bacteria for bulk organic and nutrient removal. For example, the Cytophaga-Flavobacter cluster is thought to contain major bacterial groups capable of dissolved organic matter consumption (Cottrell and Kirchman, 2000). Despite the variation of bacterial population, this cluster was consistently abundant $(>15 \%)$ for all conditions, explaining the consistently high removal of bulk organics.

The anoxic-aerobic MBR system was designed for nitrogen removal via nitrification/denitrification pathways by facilitating exposure of sludge to alternate anoxic/aerobic conditions. Autotrophic nitrification, the stepwise oxidation of ammonia to nitrate, is catalyzed by two different functional groups of microorganisms. First, ammonia is oxidized via hydroxylamine to nitrite by AOB. Nitrite then is released and serves as a substrate for NOB, which further oxidize it to nitrate, the end product of aerobic nitrification. Despite the efficient ammonia oxidation (ammonia in permeate was

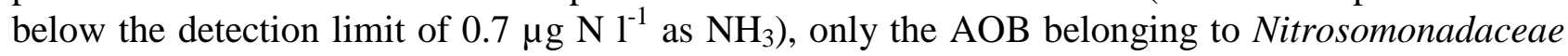
were detected and that too at very low abundance $(<0.2 \%)$ (Figure 5$)$. The observation made in the current study is consistent with previous studies, e.g. Zhang et al. (2011). Possibly Nitrosomonas has high transcription activity despite the low abundance in activated sludge. It is also possible that there were unidentified AOBs in the activated sludge. Indeed the role of ammonia oxidizing archaea (AOA) in removing ammonia (Zhang et al., 2011; Helbling et al., 2012) has been reported. Unfortunately, the primers designed for this study targeted only bacteria, not archaea.

Complete nitrification was achieved throughout the study. Notably only the Nitrospira-like NOBs were detected in this study irrespective of the SRT, although lower relative abundance of Nitrospira-like NOBs was noted under the shorter SRT $(2.8 \pm 0.5 \%, n=2$ for infinite SRT vs. 0.6 $\pm 0.2 \%, n=6$, for $25 \mathrm{~d}$ SRT) (Figure 5). The observed key role of the Nitrospira-like NOB is in line with previous studies (Chiellini et al., 2013). The competitive abundance of the Nitrospira-like NOBs over the other NOBs (e.g., Nitrobacter) may be attributed to their survival strategy. The usually low transient nitrite concentration in MBR because of high SRT (leading to low F/M ratio) favour the growth of the K-strategists Nitrospira (Chiellini et al., 2013).

Since ammonia removal via nitrification proceeds in the aerobic zone, stopping IR did not induce any impact on this process. Microbial community data verifies that AOB and NOB communities remained virtually unchanged when IR was ceased (Figure 5). By contrast, overall TN removal reduced by around $50 \%$ within $10 \mathrm{~d}$ of stopping recirculation because this ceased the supply of nitrate to the anoxic zone which is required for the denitrification process. Many bacterial groups have denitrifying capacity, and, in situ observation of their role in activated sludge would be rather complicated. Therefore, only the bacteria that are well known for their denitrifying role in activated sludge have been closely analysed here. These include Hyphomicrobium, Rhodobacter, Acidovorax, Comamonas, Dechloromonas, Thauera, and Zoogloea (Nielsen and Seviour, 2010; Guo et al., 
2013). Under an IR ratio of 3 (Conditions 1, 2 and 3), these bacteria showed stable abundance (1.2 $1.4 \%$ ) in the anoxic bioreactor. IR cessation did not change the abundance in the anoxic bioreactor, but significantly disrupted overall denitrification due to lack of supply of nitrate (Figure 5).

\section{[Figure 5]}

Integral to biological phosphorous removal are alternate exposure to anaerobic and aerobic conditions (i.e., IR between the bioreactors) and sludge withdrawal (Phan et al., 2014). The role of PAOs in the current study is evident from the significant accumulation of phosphorus in the anoxic reactor in absence of either sludge withdrawal (Condition 1) or IR (Condition 4). Consistent with the trend of phosphorus removal, "Candidatus Accumulibacter", which is a key PAO, showed higher abundance in presence of IR $(5.8 \pm 0.8 \%, n=4$ vs. $0.2 \pm 0.2 \%, n=2)$ (Figure 5). Furthermore, with IR, their relative abundance was significantly higher under an SRT of $25 \mathrm{~d}(5.8 \pm$ $0.8 \%, n=4)$ than with infinite SRT i.e., no sludge withdrawal $(1.9 \pm 0.1 \%, n=2)$. The relative abundance correlated well with the phosphorus removal performance (Table 2). It is noteworthy that this PAO group is also regarded as an important denitrifying group (Nielsen and Seviour, 2010). Their higher relative abundance compared to other denitrifying groups (Figure 5) possibly demonstrates their important role in denitrification too.

Plantomycetes was found to be the third dominant phylum in the presence of both IR and TrOC (5$10 \%$ ), but they were detected only at low relative abundances of around $1.5 \%$ when either IR or TrOC was absent (Figure 2). It is notable that, anammox bacteria, which belong to the order of the Brocadiales, are affiliated to the Plantomycetes (Nielsen and Seviour, 2010). About 30 - 50\% of the global marine nitrogen loss is attributed to the activity of these anammox bacteria. A bacterial group affiliated with Plantomycetes was noted to induce significant nitrogen removal in a moving bed biofilm reactor, likely via an anammox pathway (van Kessel et al., 2010). High relative abundance of Plantomycetes and their reduction due to cessation of IR in the current study suggest their very probable role in TN removal. Coexistence of nitrifying, anammox and denitrifying bacteria was reported in a sequencing batch reactor (Langone et al., 2014). Their reduction in the absence of TrOC (Condition 2) also indicates their relationship with TrOC transformation as discussed in the next section.

\subsubsection{Correlation between TrOC biodegradation and bacterial community}

In this study, TOC, TN and TP removals were unaffected by the operating SRT. However, better removal of two recalcitrant compounds namely carbamazepine and gemfibrozil was observed in absence of sludge withdrawal (i.e., infinite SRT) (Table 3). Analysis of the bacterial community in the present study suggests that this difference in TrOC removal may be related to the diversity of microbial communities. Longer SRT resulted in higher bacterial diversity as demonstrated by $\alpha$ diversity indices (Table 4) and taxonomic profile (Figure 2 and Figure 3). Higher microbial diversity may lead to a more diverse enzymatic profile (Ittisupornrat et al., 2014), which may achieve better removal of recalcitrant compounds. For example, Burkholderiales was found to be more abundant under infinite SRT (Condition 1). This bacterial order was previously identified to be predominant in sludge treating sulfamethoxazone (Esplugas et al., 2013) and also in chlorinated aliphatics and aromatic hydrocarbon-contaminated groundwater (Abbai and Pillay, 2013). Boonnorat et al. (2014) found higher biodegradation of eight TrOCs in MBR under no sludge wastage.

Stopping recirculation in between anoxic/aerobic reactor did not induce any impact on nitrification. Indeed, microbial community analysis verifies that AOB and NOB communities were unaffected by stopping IR (Figure 5). Consistent with that, similarly high biodegradation of TrOCs in the aerobic bioreactor continued in absence of IR. This indicates a pivotal role of nitrifiers in TrOC removal, which is consistent with recent literature (Helbling et al., 2012; Tran et al., 2013). 
The reported TrOC removal data demonstrates that anoxic conditions may enhance the removal of nine of the 30 TrOCs studied (Supplementary data Table S4). However, when IR was absent, the anoxic removal of some compounds namely, triclosan, amitriptyline, 4-tert-octylphenol, benzophenol and octocrylene occurred mainly via adsorption to sludge (Data not shown), suggesting a low TrOC transformation capacity. Stopping recirculation led to the deterioration of denitrification and hence TN removal. The microbial community data clearly illustrates significant reduction of denitrifying bacteria in the anoxic reactor (Figure 5). This impact of IR on the bacterial structure explains the low TrOC biodegradation by the anoxic sludge under no IR. Some isolated/enriched representatives of denitrifiers have been shown to possess TrOC degradation capacity (Ismail and Chiang, 2011). Most prevalent among these in this study are the members affiliated with Rhodocyclaceae that showed significantly higher relative abundance (around 10\%) in the presence of IR than in its absence (around 5\%).

The change in abundance of Plantomycetes due to TrOC addition in this study is interesting. This change was driven by the bacterial phylotypes affiliated with Gemmataceae, Pirellulaceae and Planctomycetaceae. Under an IR of 3, their relative abundance was higher in presence of TrOCs (4.4 $\pm 0.5 \%, n=4$ vs. $0.5 \pm 0.1 \%, n=2)$ (Figure 3), which suggests their involvement in TrOC transformation. Indeed genomic analysis of 11 representatives of Plantomycetales revealed their capacity to degrade diverse toxic compounds including ethylbenzene, aminobenzoate, naphthalene, bisphenol A, chloroxyclohexane and polycyclic aromatic hydrocarbon (Guo et al., 2014). Furthermore, it is notable that the relative abundance of the Plantomycetes decreased significantly $(0.4 \pm 0.2 \%, n=2)$ when IR was stopped (Supplementary data Table S6), which coincides with the period when nitrogen removal was significantly affected (Table 2). Thus the members of Plantomycetes were probably also involved in nitrogen removal. Nitrogen removal by this group may be attributed to the anammox process; however, this speculation needs to be verified.

After stopping IR, aerobic TrOC biotransformation was not affected significantly, while a reduced TrOC biotransformation by the anoxic sludge was observed (Supplementary Data Table S3). Overall the TrOC removal by the MBR was stable. This indicates a key role of the aerobic reactor in TrOC degradation. In order to derive a clearer understanding of the bacteria that may have played a pivotal role in TrOC degradation, the bacteria that developed abundantly in aerobic sludge under no IR condition (but showed rare or no presence in the anoxic sludge) were closely examined. The most abundant bacteria in aerobic sludge under a no IR condition were the members of the order Myxococcales. This order accounted for more than 33\% in aerobic sludge, but was only present at less than $0.3 \%$ in the anoxic sludge which showed low TrOC transformation in absence of IR (Figure 4). Their capacity of excreting hydrolytic enzymes and decomposing various complex biopolymers (Garrity et al., 2006) possibly contributed to biotransformation of TrOCs. The members of the order Methylococcales also may have played an important role in TrOC transformation. In absence of IR, this bacterial order was not detected in anoxic sludge.

The bacteria that appeared in sludge only when the influent contained TrOCs may be relevant to TrOC biodegradation. Notably, the members of the order Methylophilales grew in sludge treating TrOCs in Condition $1(\sim 3.7 \pm 0.8 \%)$, but disappeared when TrOC addition was stopped in Condition 2. However, they strongly reappeared to become the most abundant group (32 $\pm 2 \%$ ) when TrOC addition was resumed in Condition 3 (Figure 3). When IR was stopped, their relative abundance again reduced to $4.9 \%$ and $6.6 \%$ in anoxic and aerobic sludge, respectively (Figure 4). Their ability to degrade microcystin, a cyanobacterial toxin bearing nitrogen in its cyclic structure (Mou et al., 2013) may indicate their capacity of degrading TrOCs. Notably, members belonging to Methylophilales are obligate methylotrophs that only grow on reduced carbon compounds containing no C-C bonds such as methane, methanol, and methylated amines (Ginige et al., 2004). In the current study, the possible source of carbon in the synthetic wastewater was glucose, peptone, acetate and urea, which do not satisfy the C-C bond-related criteria for the methylotrophs. Thus there is a possibility that the members of Methylophilales utilized some TrOCs as the carbon source. 
In this study, TrOCs such as formononetin, ametryn, ibuprofen, ketoprofen, primidone, and naproxen (all without C-C bonds) (Supplementary data Table S2) potentially provided a carbon source for the growth of Methylophilales. This aspect needs further verification, but is beyond the scope of this study.

\section{Conclusions}

The bacterial communities developed in the anoxic and aerobic bioreactors of the integrated anoxicaerobic MBR were highly similar in structure and phylogenetic relationship due to internal recirculation (IR). This confirms IR is a key driving force shaping bacterial communities in the anoxic-aerobic MBR system. In the absence of IR, significantly different microbial communities developed in anoxic and aerobic bioreactors, consequently leading to significantly low nutrient and TrOC removal capacity of the anoxic bioreactor. Higher bacterial diversity under the longer SRT was evident; however, except for a few TrOCs the removal of TOC, TN and TrOCs were the same irrespective of the SRT. TrOC addition also induced shifts in bacterial communities, and UniFrac analysis (based on relative abundance of bacterial phylotypes) as well as taxonomic profile analysis indicated a relationship between microbial communities and TrOC biotransformation. Members within the order Methylophilales and Myxococcales are highly likely to be involved in TrOC biotransformation. Other candidates are phylotypes within Burkhoderiales and Lactobacillales and the nitrogen-removing bacteria such as the members within Plantomycetes and Rhodocyclales. The members of Cytophagaceae seemed unlikely to contribute to TrOC biotransformation.

\section{Acknowledgements}

Hop V. Phan thanks the University of Wollongong (Australia) and the Thanh Hoa provincial government (Viet Nam) for a joint PhD scholarship. Thanks are due to Zenon Environmental Inc., Canada for supplying the membrane module. University of Wollongong is gratefully acknowledged for the provision of a Research Partnership Grant with industry support from Shoalhaven Water (NSW).

\section{References}

Abbai, N.S., Pillay, B., 2013. Analysis of hydrocarbon-contaminated groundwater metagenomes as revealed by high-throughput sequencing. Molecular Biotechnology 54, 900-912.

Alidina, M., Li, D., Drewes, J.E., 2014. Investigating the role for adaptation of the microbial community to transform trace organic chemicals during managed aquifer recharge. Water Research 56, 172-180.

Boonnorat, J., Chiemchaisri, C., Chiemchaisri, W., Yamamoto, K., 2014. Microbial adaptation to biodegrade toxic organic micro-pollutants in membrane bioreactor using different sludge sources. Bioresource Technology 165, 50-59.

Briones, A., Raskin, L., 2003. Diversity and dynamics of microbial communities in engineered environments and their implications for process stability. Current Opinion in Biotechnology 14, 270-276.

Caporaso, J.G., Bittinger, K., Bushman, F.D., DeSantis, T.Z., Andersen, G.L., Knight, R., 2010a. PyNAST: a flexible tool for aligning sequences to a template alignment. Bioinformatics (Oxford, England) 26, 266-267.

Caporaso, J.G., Kuczynski, J., Stombaugh, J., Bittinger, K., Bushman, F.D., Costello, E.K., Fierer, N., Pẽa, A.G., Goodrich, J.K., Gordon, J.I., Huttley, G.A., Kelley, S.T., Knights, D., Koenig, J.E., Ley, R.E., Lozupone, C.A., McDonald, D., Muegge, B.D., Pirrung, M., Reeder, J., Sevinsky, J.R., Turnbaugh, P.J., Walters, W.A., Widmann, J., Yatsunenko, T., Zaneveld, J., Knight, R., 2010b. QIIME allows analysis of high-throughput community sequencing data. Nature Methods 7, 335336. 
Caracciolo, A.B., Bottoni, P., Grenni, P., 2010. Fluorescence in situ hybridization in soil and water ecosystems: A useful method for studying the effect of xenobiotics on bacterial community structure. Toxicological and Environmental Chemistry 92, 567-579.

Chiellini, C., Munz, G., Petroni, G., Lubello, C., Mori, G., Verni, F., Vannini, C., 2013.

Characterization and comparison of bacterial communities selected in conventional activated sludge and membrane bioreactor pilot plants: A focus on nitrospira and planctomycetes bacterial phyla. Current Microbiology 67, 77-90.

Cottrell, M.T., Kirchman, D.L., 2000. Natural Assemblages of Marine Proteobacteria and Members of the Cytophaga-Flavobacter Cluster Consuming Low- and High-Molecular-Weight Dissolved Organic Matter. Applied and Environmental Microbiology 66, 1692-1697.

Eaton, A.D., Clescerl, L.S., Rice, E.W., Greenberg, A.E., 2005. Standard Methods for Examination of Water \& Wastewater, 21st ed. American Public Health Association, Washington, D. C.

Edgar, R., 2010. Search and clustering orders of magnitude faster than BLAST. Bioinformatics 26, 2460 - 2461.

Esplugas, M., González, O., Sans, C., 2013. Bacterial community characterization of a sequencing batch reactor treating pre-ozonized sulfamethoxazole in water. Environmental Technology (United Kingdom) 34, 1583-1591.

Garrity, G., Brenner, D.J., Staley, J.T., Krieg, N.R., Boone, D.R., De Vos, P., Goodfellow, M., Rainey, F.A., Schleifer, K.H., 2006. Bergey's Manual ${ }^{\circledR}$ of Systematic Bacteriology: Volume Two: The Proteobacteria (Part C). Springer.

Ginige, M.P., Hugenholtz, P., Daims, H., Wagner, M., Keller, J., Blackall, L.L., 2004. Use of Stable-Isotope Probing, Full-Cycle rRNA Analysis, and Fluorescence In Situ HybridizationMicroautoradiography To Study a Methanol-Fed Denitrifying Microbial Community. Applied and Environmental Microbiology 70, 588-596.

Gómez-Silván, C., Vílchez-Vargas, R., Arévalo, J., Gómez, M.A., González-López, J., Pieper, D.H., Rodelas, B., 2014. Quantitative response of nitrifying and denitrifying communities to environmental variables in a full-scale membrane bioreactor. Bioresource Technology 169, 126133.

Guo, F., Ju, F., Cai, L., Zhang, T., 2013. Taxonomic Precision of Different Hypervariable Regions of 16S rRNA Gene and Annotation Methods for Functional Bacterial Groups in Biological Wastewater Treatment. PLoS ONE 8, e76185.

Guo, M., Zhou, Q., Zhou, Y., Yang, L., Liu, T., Yang, J., Chen, Y., Su, L., Xu, J., Chen, J., Liu, F., Chen, J., Dai, W., Ni, P., Fang, C., Yang, R., 2014. Genomic evolution of 11 type strains within family Planctomycetaceae. PLoS ONE 9, e86752.

Hai, F.I., Tessmer, K., Nguyen, L.N., Kang, J., Price, W.E., Nghiem, L.D., 2011. Removal of micropollutants by membrane bioreactor under temperature variation. Journal of Membrane Science 383, 144-151.

Helbling, D.E., Johnson, D.R., Honti, M., Fenner, K., 2012. Micropollutant biotransformation kinetics associate with WWTP process parameters and microbial community characteristics. Environmental Science and Technology 46, 10579-10588.

Ismail, W., Chiang, Y., 2011. Oxic and anoxic metabolism of steroids by bacteria. Journal of Bioremediation \& Biodegradation (S) 1, 2 - 13.

Ittisupornrat, S., Tobino, T., Yamamoto, K., 2014. A study of the relationship among sludge retention time, bacterial communities, and hydrolytic enzyme activities in inclined plate membrane bioreactors for the treatment of municipal wastewater. Appl Microbiol Biotechnol 98, 9107-9118.

Langone, M., Yan, J., Haaijer, S.C.M., Op Den Camp, H.J.M., Jetten, M., Andreottola, G., 2014. Coexistence of nitrifying, anammox and denitrifying bacteria in a sequencing batch reactor. Frontiers in Microbiology 5, 28. doi: 10.3389/fmicb.2014.00028. 
Lozupone, C., Knight, R., 2005. UniFrac: A new phylogenetic method for comparing microbial communities. Applied and Environmental Microbiology 71, 8228-8235. Lozupone, C.A., Hamady, M., Kelley, S.T., Knight, R., 2007. Quantitative and Qualitative $\beta$ Diversity Measures Lead to Different Insights into Factors That Structure Microbial Communities. Applied and Environmental Microbiology 73, 1576-1585.

Luo, Y., Guo, W., Ngo, H.H., Nghiem, L.D., Hai, F.I., Zhang, J., Liang, S., Wang, X.C., 2014. A review on the occurrence of micropollutants in the aquatic environment and their fate and removal during wastewater treatment. Science of The Total Environment 473-474, 619-641.

Luo, W., Phan, H.V., Hai, F.I., Price, W.E., Guo, W., Ngo, H.H., Yamamoto, K., Nghiem, L.D., 2016. Effects of salinity build-up on the performance and bacterial community structure of a membrane bioreactor. Bioresource Technology 200, 305-310.

Mou, X., Lu, X., Jacob, J., Sun, S., Heath, R., 2013. Metagenomic Identification of Bacterioplankton Taxa and Pathways Involved in Microcystin Degradation in Lake Erie. PLoS ONE 8, e61890.

Navaratna, D., Elliman, J., Cooper, A., Shu, L., Baskaran, K., Jegatheesan, V., 2012. Impact of herbicide Ametryn on microbial communities in mixed liquor of a membrane bioreactor (MBR). Bioresource Technology 113, 181-190.

Nielsen, P.H., Seviour, R., 2010. Microbial ecology of activated sludge, $1^{\text {st }}$ ed. IWA Publishing, London.

Phan, H.V., Hai, F.I., Kang, J., Dam, H.K., Zhang, R., Price, W.E., Broeckmann, A., Nghiem, L.D., 2014. Simultaneous nitrification/denitrification and trace organic contaminant (TrOC) removal by an anoxic-aerobic membrane bioreactor (MBR). Bioresource Technology 165, 96-104.

Rabia, A., Shah, N.P., 2011. Antibiotic resistance of probiotic organisms and safety of probiotic dairy products. International Food Research Journal 18, 837 - 853.

Stadler, L.B., Su, L., Moline, C.J., Ernstoff, A.S., Aga, D.S., Love, N.G., 2015. Effect of redox conditions on pharmaceutical loss during biological wastewater treatment using sequencing batch reactors. Journal of Hazardous Materials 282, 106-115.

Steiert, J.G., Crawford, R.L., 1986. Catabolism of pentachlorophenol by a Flavobacterium sp. Biochemical and Biophysical Research Communications 141, 825-830.

Tadkaew, N., Hai, F.I., McDonald, J.A., Khan, S.J., Nghiem, L.D., 2011. Removal of trace organics by MBR treatment: The role of molecular properties. Water Res. 45, 2439-2451.

Thayanukul, P., Zang, K., Janhom, T., Kurisu, F., Kasuga, I., Furumai, H., 2010. Concentrationdependent response of estrone-degrading bacterial community in activated sludge analyzed by microautoradiography-fluorescence in situ hybridization. Water Research 44, 4878-4887.

Tran, N.H., Urase, T., Ngo, H.H., Hu, J., Ong, S.L., 2013. Insight into metabolic and cometabolic activities of autotrophic and heterotrophic microorganisms in the biodegradation of emerging trace organic contaminants. Bioresource Technology 146, 721-731.

van Kessel, M.A.H.J., Harhangi, H.R., van de Pas-Schoonen, K., van de Vossenberg, J., Flik, G., Jetten, M.S.M., Klaren, P.H.M., Op den Camp, H.J.M., 2010. Biodiversity of N-cycle bacteria in nitrogen removing moving bed biofilters for freshwater recirculating aquaculture systems. Aquaculture 306, 177-184.

Vuono, D.C., Benecke, J., Henkel, J., Navidi, W.C., Cath, T.Y., Munakata-Marr, J., Spear, J.R., Drewes, J.E., 2015. Disturbance and temporal partitioning of the activated sludge metacommunity. Isme J. 9, 425-435.

Wijekoon, K.C., Hai, F.I., Kang, J., Price, W.E., Guo, W., Ngo, H.H., Nghiem, L.D., 2013. The fate of pharmaceuticals, steroid hormones, phytoestrogens, UV-filters and pesticides during MBR treatment. Bioresource Technology 144, 247-254. 
698 Xia, S., Jia, R., Feng, F., Xie, K., Li, H., Jing, D., Xu, X., 2012. Effect of solids retention time on 699 antibiotics removal performance and microbial communities in an A/O-MBR process. Bioresource 700 Technology 106, 36-43.

701 Zang, K., Kurisu, F., Kasuga, I., Furumai, H., Yagi, O., 2008. Analysis of the phylogenetic diversity 702 of estrone-degrading bacteria in activated sewage sludge using microautoradiography-fluorescence 703 in situ hybridization. Systematic and Applied Microbiology 31, 206-214.

704 Zhang, T., Shao, M.F., Ye, L., 2012. 454 Pyrosequencing reveals bacterial diversity of activated 705 sludge from 14 sewage treatment plants. Isme J. 6, 1137-1147.

706 Zhang, T., Ye, L., Tong, A., Shao, M.-F., Lok, S., 2011. Ammonia-oxidizing archaea and ammonia707 oxidizing bacteria in six full-scale wastewater treatment bioreactors. Appl Microbiol Biotechnol 91, $708 \quad 1215-1225$.

709

710 


\section{Highlights}

- Recirculation between reactors greatly influenced MBR bacterial community makeup.

- $\quad$ Longer sludge retention time resulted in higher bacterial diversity.

- Trace organic contaminant (TrOC) addition induced shifts in bacterial communities.

- Without recirculation the bacteria in anoxic regime removed nutrient/TrOC poorly.

- Potential TrOC degrading bacteria include members of Methylophilales and Myxococcales. 


\section{List of Figures}

2 Figure 1: Analysis of bacterial communities with unweighted and weighted UniFrac 3 visualized by hierarchical clustering of Pair Group Method with Arithmetic mean (UPGMA) 4 and Principal coordinated analysis (PCoA). (A) and (B) are hierarchical cluster diagram for UPGMA with unweighted UniFrac and weighted UniFrac, respectively, and (C) and (D) are PCoA with unweighted and weighted UniFrac, respectively.

Figure 2: Relative abundance of bacterial phyla. 'Unclassified' indicates the sequences that could not be classified up to the phylum level. Phyla that were observed at less than $1 \%$ average abundance were grouped in 'Minor phyla' (see also Supplementary data Table S5).

Figure 3: Relative abundance of the bacterial phylotypes at the deepest level of classification (order, family or genus) revealed by the data analysed. Anoxic and oxic samples were collected during operation under an IR of 3 and on day 152 (Condition 1: Infinite SRT, with TrOC), 225 (Condition 2: 25 d SRT, no TrOC), and 265 (Condition 3: 25 d SRT, with TrOC) - The bacterial phylotypes showing at least an average relative abundance of $2 \%$ were arranged from the bottom to top in the following sequence: more relative abundance under infinite SRT, more relative abundance under an SRT of $25 \mathrm{~d}$, more relative abundance with TrOC addition, more relative abundance with no TrOC addition and, finally, no significant change. The protocol used in this study could provide information up to the genus level, but in some cases analysed data fell short to reveal the genus ("g__), family ("f__") or even the order (“o__").

Figure 4: Relative abundance of the bacterial phylotypes at the deepest level of classification (order, family or genus) revealed by the data analysed. Anoxic and oxic samples were collected on day 265 (Condition 3: 25 d SRT, with TrOC addition, and IR = 3) and 304 (Condition 4: $25 \mathrm{~d}$ SRT, with TrOC addition, and IR $=0$ ). The bacterial phylotypes showing at least an average relative abundance of $2 \%$ were arranged from the bottom to top in the following sequence: Significant reduction in Condition 4, most abundant in anoxic sample in Condition 4, most abundant in aerobic sample in Condition 4, and finally no significant change due to cessation of IR. The protocol used in this study could provide information up to the genus level, but in some cases analysed data fell short to reveal the genus ("g_"), family ("f__") or even the order ("o__").

Figure 5: Relative abundance of potential functional bacterial groups including ammonia oxidizing bacteria (AOB: Nitrosomonadaceae), nitrite oxidizing bacteria (NOB: Nitrospira), polyphosphate accumulating organisms (PAO: “Candidatus Accumulibacter”), and denitrifers (Hyphomicrobium, Rhodobacter, Acidovorax, Comamonas, Dechloromonas, Thauera and Zoogloea). Anoxic and oxic samples were collected on day 152 (Condition 1: IR of 3, Infinite SRT, with TrOC), 225 (Condition 2: IR of 3, 25 d SRT, no TrOC), 265 (Condition 3: IR of 3, 25 d SRT, with TrOC) and 304 (Condition 4: IR = 0, 25d SRT, with TrOC). 


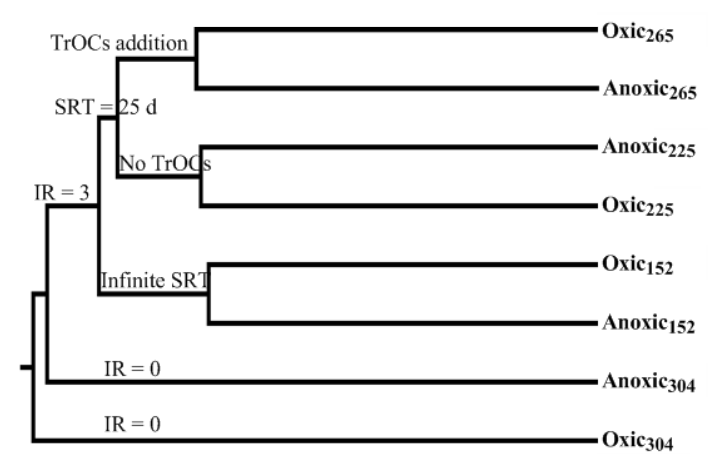

(A) UPGMA with unweighted UniFrac

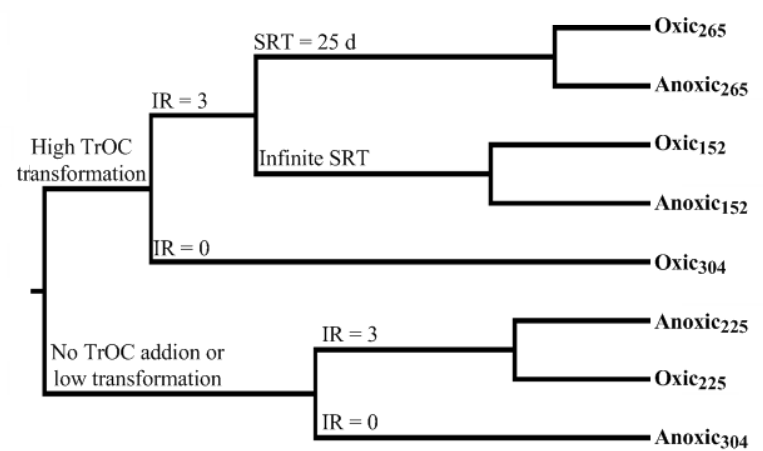

(B) UPGMA with weighted UniFrac

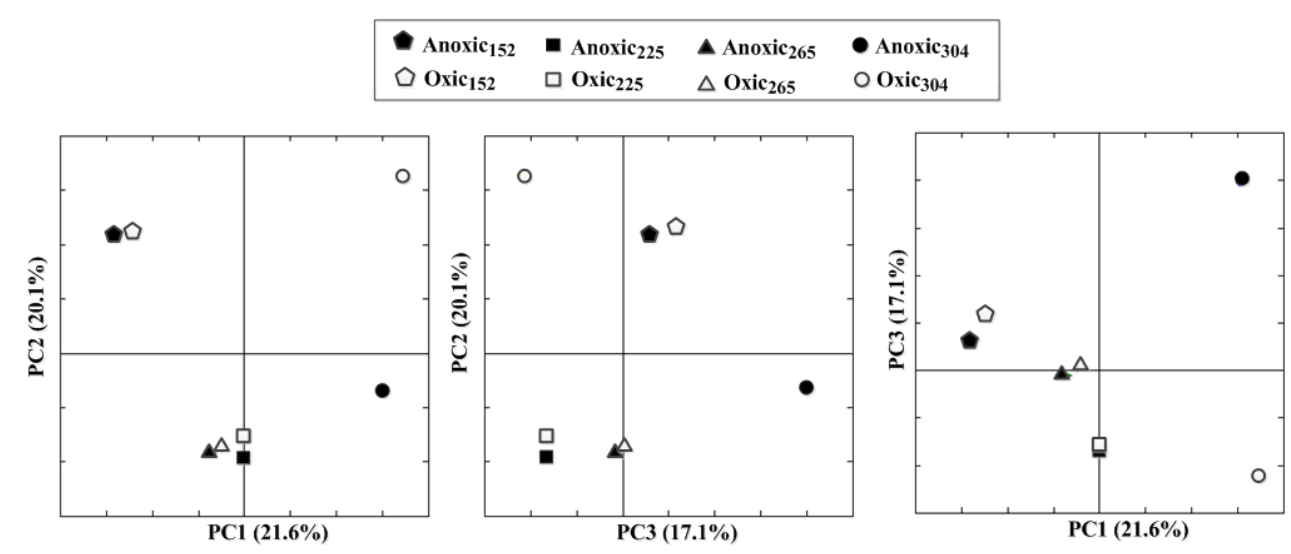

(C) PCoA with unweighted UniFrac
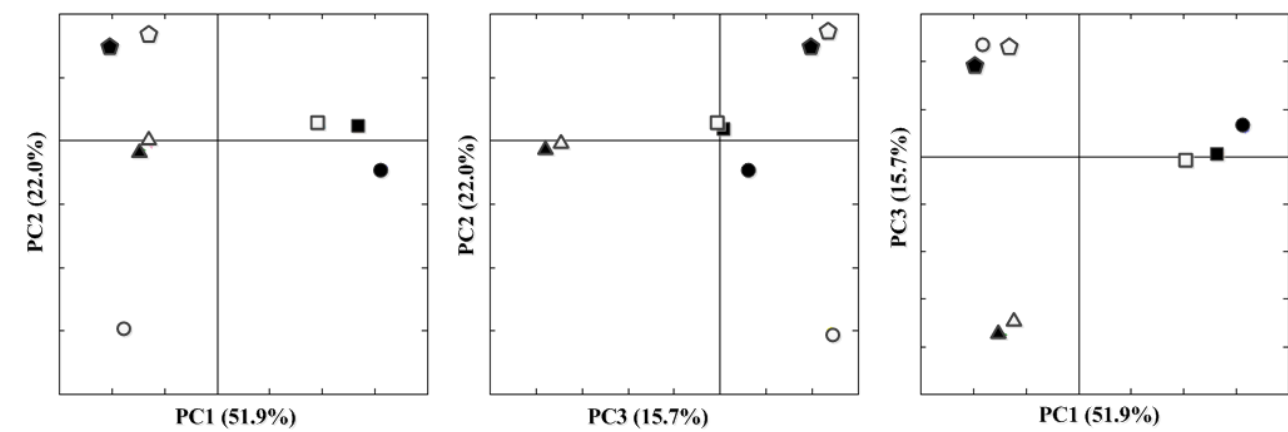

(D) PCoA with weighted UniFrac

Figure 1 


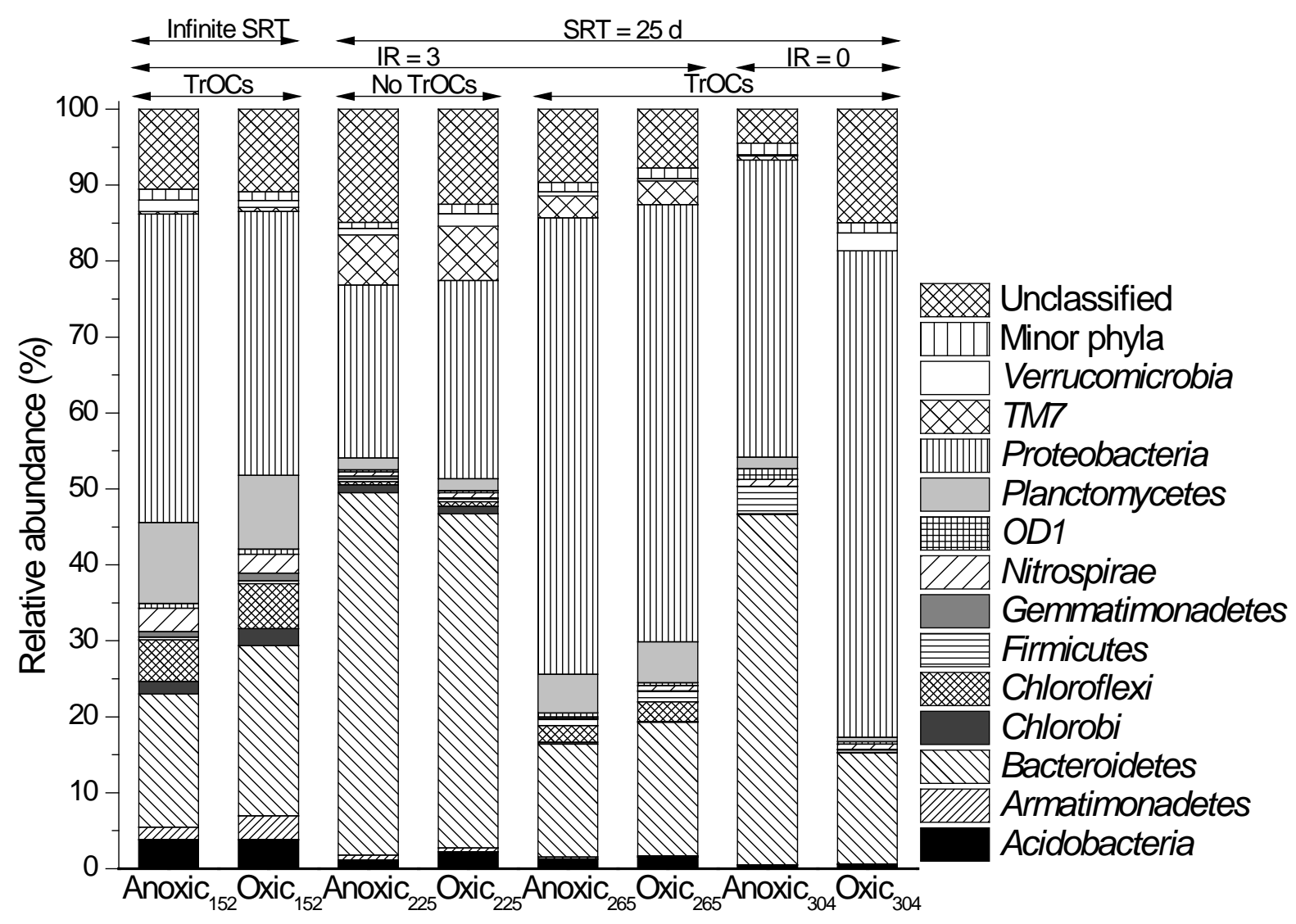

Figure 2 


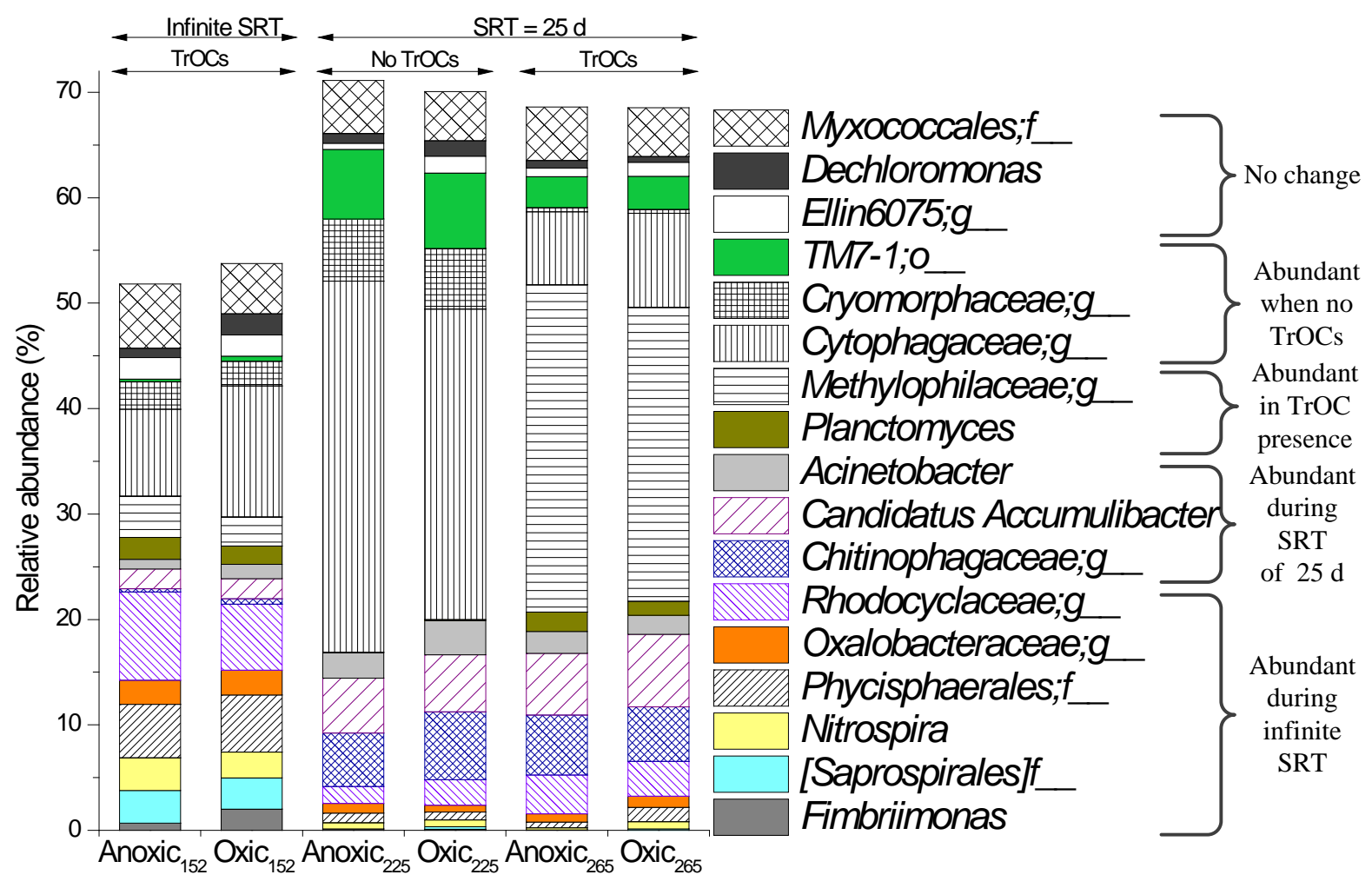

Figure 3
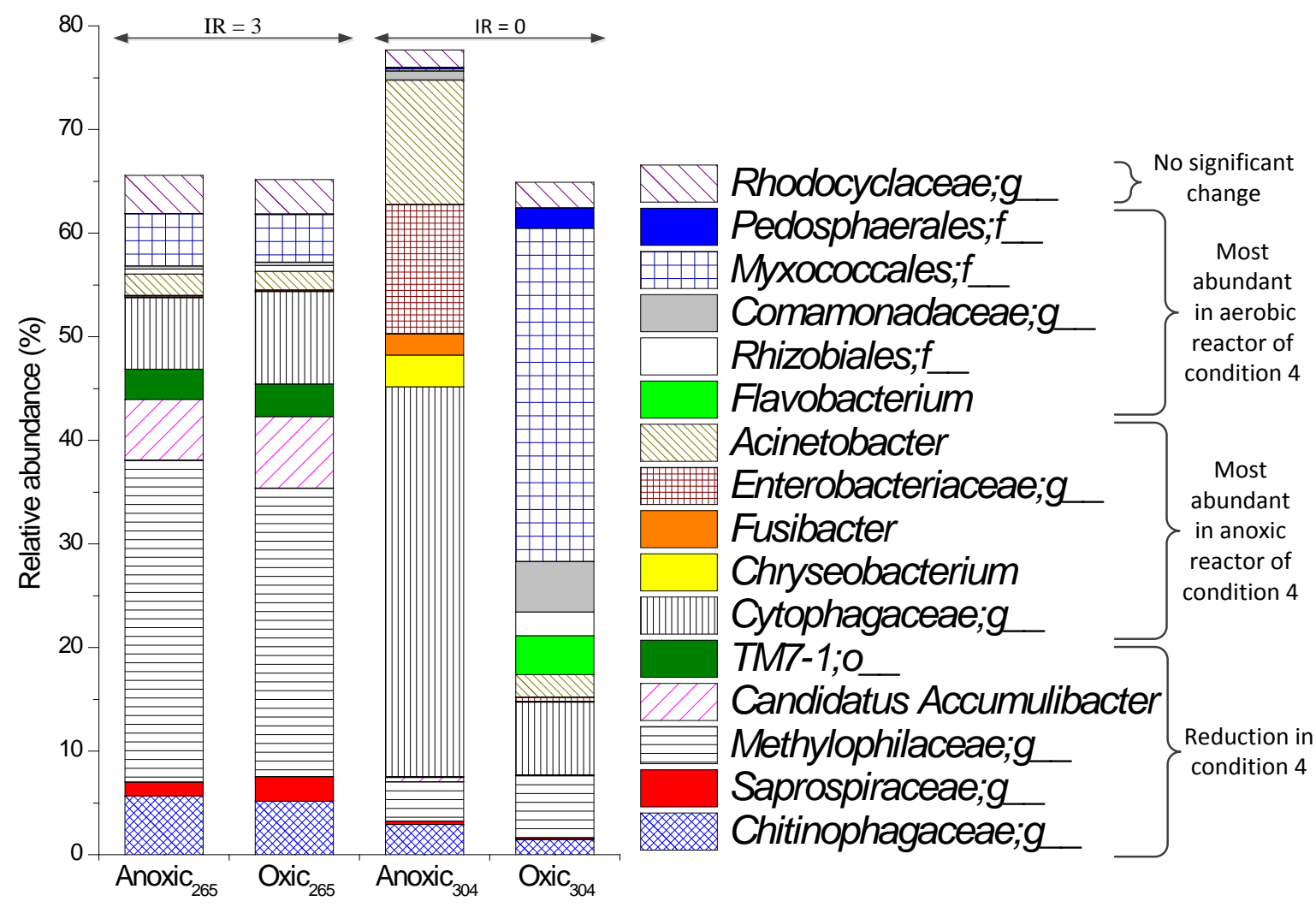

Figure 4 


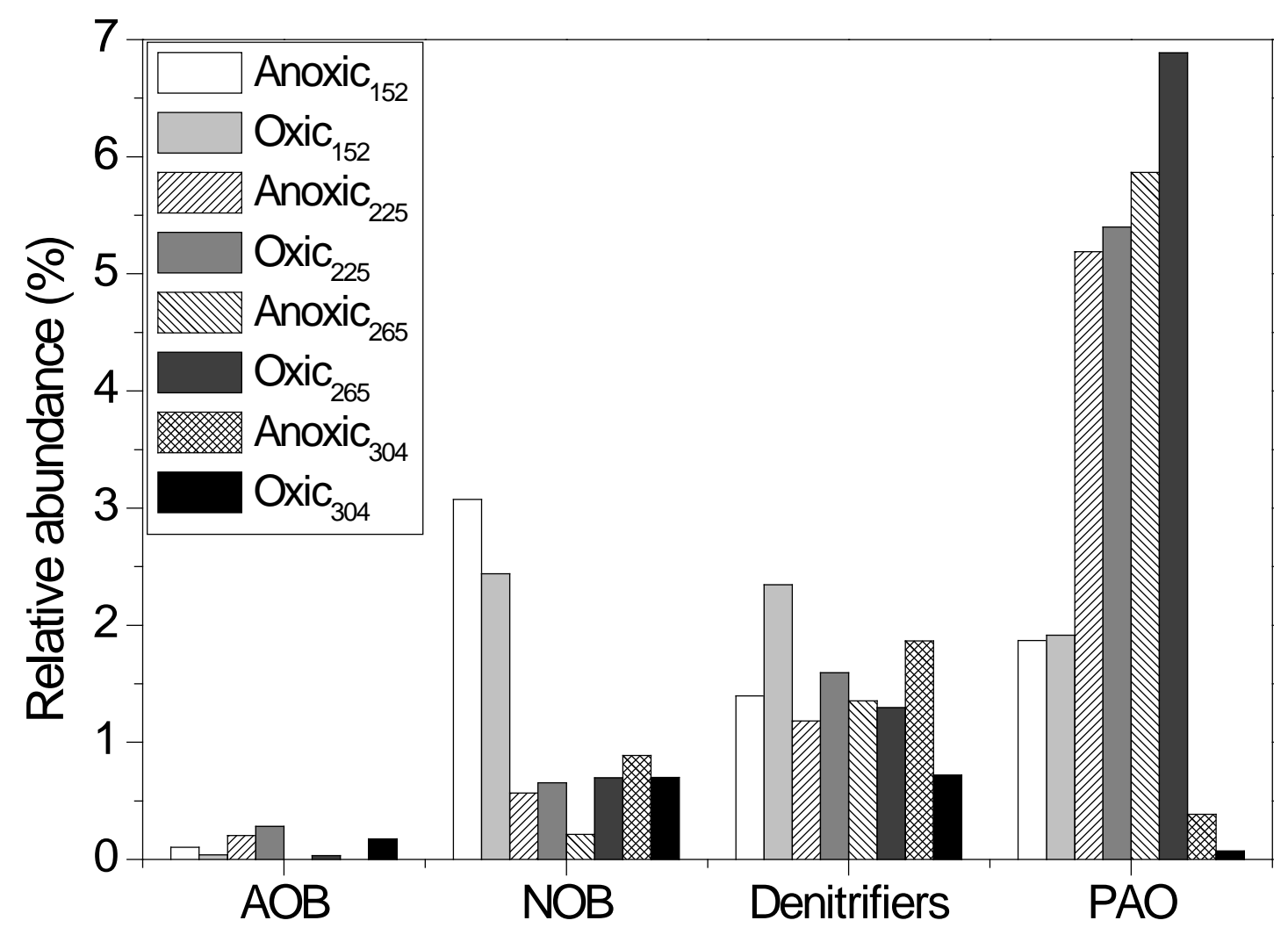

Figure 5 


\section{List of Tables}

Table 1: Activated sludge samples from the anoxic-aerobic MBR for bacterial community analysis.

\begin{tabular}{|c|c|c|c|}
\hline Day & Operational regime & $\begin{array}{c}\text { Day of } \\
\text { sampling }\end{array}$ & $\begin{array}{l}\text { Sample } \\
\text { ID }\end{array}$ \\
\hline $0-125$ & $\begin{array}{l}\text { MBR start-up period: Infinite SRT }{ }^{\mathrm{a}} \text {, fine- } \\
\text { tuning IR ratio }(0.5-3) \text {, without TrOCs }\end{array}$ & \multicolumn{2}{|c|}{ No sequencing samples } \\
\hline $126-170$ & $\begin{array}{l}\text { Condition1: Infinite SRT, IR = 3, with } \\
\text { TrOCs }\end{array}$ & Day 152 & $\begin{array}{l}\text { Anoxic }_{152} \\
\text { Oxic }_{152}\end{array}$ \\
\hline $171-180$ & $\begin{array}{l}\text { Stabilizing period: Infinite SRT, IR }=3 \text {, } \\
\text { no TrOCs }\end{array}$ & \multicolumn{2}{|c|}{ No sequencing samples } \\
\hline $181-225$ & $\begin{array}{l}\text { Condition 2: SRT }=25 \text { d, IR = 3, without } \\
\text { TrOCs }\end{array}$ & Day 225 & $\begin{array}{l}\text { Anoxic }_{225} \\
\text { Oxic }_{225}\end{array}$ \\
\hline $226-265$ & $\begin{array}{l}\text { Condition 3: SRT = } 25 \text { d, IR = 3, with } \\
\text { TrOCs }\end{array}$ & Day 265 & $\begin{array}{l}\text { Anoxic }_{265} \\
\text { Oxic }_{265} \\
\end{array}$ \\
\hline $266-305$ & $\begin{array}{l}\text { Condition 4: SRT }=25 \mathrm{~d} \text {, IR }=0 \text {, with } \\
\text { TrOCs }\end{array}$ & Day 304 & $\begin{array}{l}\text { Anoxic }_{304} \\
\text { Oxic }_{304}\end{array}$ \\
\hline
\end{tabular}

Note: SRT= sludge retention time; IR= internal recirculation ratio; ${ }^{\mathrm{a}}$ No sludge withdrawal except for sampling, resulting in a theoretical SRT of $>1000 \mathrm{~d}$.

Table 2: Removal efficiency of total organic carbon and nutrients (average \pm standard deviation).

\begin{tabular}{lllll}
\hline \multirow{2}{*}{ Parameter } & \multicolumn{4}{c}{ Removal efficiency (\%) } \\
\cline { 2 - 5 } & Condition 1 & Condition 2 & Condition 3 & Condition 4 \\
\hline TOC & $94 \pm 5(\mathrm{n}=16)$ & $83 \pm 4(\mathrm{n}=18)$ & $84 \pm 1(\mathrm{n}=13)$ & $89 \pm 1(\mathrm{n}=11)$ \\
\hline $\mathrm{NH}_{4}{ }^{-}-\mathrm{N}$ & $99 \pm 1(\mathrm{n}=11)$ & $100(\mathrm{n}=10)$ & $100(\mathrm{n}=11)$ & $100(\mathrm{n}=9)$ \\
\hline $\mathrm{TN}$ & $83 \pm 3(\mathrm{n}=16)$ & $84 \pm 5(\mathrm{n}=18)$ & $89 \pm 2(\mathrm{n}=13)$ & $27 \pm 12(\mathrm{n}=11)$ \\
\hline $\mathrm{PO}_{4}{ }^{-3}-\mathrm{P}$ & $92 \pm 5(\mathrm{n}=11)$ & $97 \pm 3(\mathrm{n}=10)$ & $98 \pm 2(\mathrm{n}=11)$ & $78 \pm 37(\mathrm{n}=9)$ \\
\hline
\end{tabular}

Note: Condition 1: Infinite SRT, IR $=3$, with TrOCs; Condition 2: SRT $=25 \mathrm{~d}$, IR $=3$, no TrOCs; Condition 3: SRT $=25$ d, IR = 3, with TrOCs; Condition 4: SRT = 25 d, IR = 0, with TrOCs. 
Table 3: TrOC removal (\%) by the MBR without sludge withdrawal ('infinite' SRT) and at an SRT of $25 \mathrm{~d}$ (average \pm standard deviation, $\mathrm{n}=6$ ).

\begin{tabular}{|c|c|c|}
\hline \multirow{2}{*}{ Compounds } & \multicolumn{2}{|c|}{ Removal efficiency (\%) } \\
\hline & Infinite SRT & SRT of $25 \mathrm{~d}$ \\
\hline Diclofenac & $5.8 \pm 5.7$ & $5.7 \pm 6.0$ \\
\hline Carbamazapine & $38.9 \pm 6.5$ & $6.1 \pm 6.0$ \\
\hline Naproxen & $60.4 \pm 2.0$ & $41.1 \pm 17.0$ \\
\hline Gemfibrozil & $87.3 \pm 1.7$ & $47.8 \pm 5.5$ \\
\hline Primidone & $76.9 \pm 6.3$ & $55.0 \pm 16.4$ \\
\hline Ketoprofen & $88.4 \pm 4.9$ & $83.4 \pm 3.1$ \\
\hline Metronidazole & $94.8 \pm 1.8$ & $87.6 \pm 1.5$ \\
\hline Ibuprofen & $98.1 \pm 0.7$ & $93.3 \pm 1.4$ \\
\hline Triclosan & $96.4 \pm 0.3$ & $95.4 \pm 1.7$ \\
\hline Amitriptyline & $98.4 \pm 0.6$ & $97.6 \pm 1.1$ \\
\hline Salicylic acid & $99.1 \pm 0.3$ & $98.9 \pm 0.4$ \\
\hline Benzophenone & $95.9 \pm 3.0$ & $92.8 \pm 7.1$ \\
\hline Oxybenzone & $98.5 \pm 0.2$ & $93.1 \pm 2.1$ \\
\hline Octocrylene & $92.0 \pm 7.6$ & $95.5 \pm 3.8$ \\
\hline Atrazine & $5.8 \pm 6.0$ & $5.7 \pm 5.6$ \\
\hline Clofibric acid & $27.9 \pm 3.0$ & $15.3 \pm 6.7$ \\
\hline Propoxur & $20.0 \pm 8.8$ & $17.1 \pm 10.4$ \\
\hline Fenoprop & $49.6 \pm 9.0$ & $37.8 \pm 13.5$ \\
\hline Pentachlorophenol & $71.6 \pm 6.1$ & $58.8 \pm 5.4$ \\
\hline Ametryn & $70.5 \pm 23.4$ & $84.0 \pm 6.8$ \\
\hline $17 \alpha$-Ethinylestradiol & $93.2 \pm 3.1$ & $92.5 \pm 2.2$ \\
\hline Estriol & $98.5 \pm 1.9$ & $97.5 \pm 2.0$ \\
\hline Estrone & $99.1 \pm 0.1$ & $98.9 \pm 1.1$ \\
\hline $17 \beta$-Estradiol-17-acetate & $98.4 \pm 0.6$ & $99.4 \pm 0.5$ \\
\hline $17 \beta$-Estradiol & $99.7 \pm 0.0$ & $99.9 \pm 0.1$ \\
\hline 4-tert-Butylphenol & $94.1 \pm 1.7$ & $81.1 \pm 4.4$ \\
\hline Bisphenol A & $98.0 \pm 2.6$ & $85.4 \pm 2.5$ \\
\hline 4-tert-Octylphenol & $95.1 \pm 3.5$ & $89.0 \pm 2.3$ \\
\hline Enterolactone & $94.6 \pm 10.9$ & $64.7 \pm 16.3$ \\
\hline Formononetin & $98.0 \pm 1.3$ & $97.7 \pm 0.6$ \\
\hline
\end{tabular}


Table 4: $\alpha$-diversity indices.

\begin{tabular}{lcccccc}
\hline & & \multicolumn{5}{c}{ a-diversity indices $^{\mathrm{a}}$} \\
\cline { 3 - 7 } $\begin{array}{l}\text { Sample } \\
\text { ID }\end{array}$ & $\begin{array}{c}\text { Sequences } \\
\text { retrieved }\end{array}$ & Chao1 index & $\begin{array}{c}\text { Good's } \\
\text { coverage } \\
(\%)\end{array}$ & $\begin{array}{c}\text { Observed_chylogenetic } \\
\text { species }\end{array}$ & $\begin{array}{c}\text { Phistance_ } \\
\text { whole_tree }\end{array}$ & $\begin{array}{c}\text { Shannon } \\
\text { index }\end{array}$ \\
\hline Anoxic $_{152}$ & 5728 & $1197 \pm 154$ & 82 & $536 \pm 9$ & $47.08 \pm 0.77$ & $7.42 \pm 0.04$ \\
\hline Oxic $_{152}$ & 5331 & $1272 \pm 146$ & 82 & $545 \pm 12$ & $47.43 \pm 0.81$ & $7.41 \pm 0.04$ \\
\hline Anoxic $_{225}$ & 1946 & $545 \pm 14$ & 91 & $320 \pm 2$ & $32.80 \pm 0.09$ & $5.48 \pm 0.01$ \\
\hline Oxic $_{225}$ & 3203 & $793 \pm 63$ & 88 & $372 \pm 13$ & $35.07 \pm 0.96$ & $6.00 \pm 0.03$ \\
\hline Anoxic $_{265}$ & 4654 & $851 \pm 93$ & 87 & $395 \pm 15$ & $36.30 \pm 1.22$ & $5.84 \pm 0.09$ \\
\hline Oxic $_{265}$ & 3165 & $852 \pm 70$ & 87 & $396 \pm 9$ & $34.25 \pm 0.77$ & $6.04 \pm 0.05$ \\
\hline Anoxic $_{304}$ & 3375 & $473 \pm 78$ & 93 & $230 \pm 9$ & $25.31 \pm 0.85$ & $4.60 \pm 0.06$ \\
\hline Oxic $_{304}$ & 5714 & $959 \pm 90$ & 86 & $408 \pm 13$ & $35.07 \pm 0.75$ & $6.32 \pm 0.04$ \\
\hline
\end{tabular}

${ }^{\mathrm{a}}$ Estimated at a sequencing depth of 1900 sequences per sample; iteration number, $\mathrm{n}=10$. 


\section{Bacterial Community Dynamics in an Anoxic-Aerobic Membrane Bioreactor - Impact on Nutrient and Trace Organic Contaminant Removal}

Hop V. Phan ${ }^{\mathrm{a}}$, Faisal I. Hai ${ }^{\mathrm{a} *}$, Ren Zhang ${ }^{\mathrm{b}}$, Jinguo Kang ${ }^{\mathrm{a}, \mathrm{c}}$, William E. Price ${ }^{\mathrm{c}}$, Long D. Nghiem $^{\mathrm{a}}$

${ }^{a}$ Strategic Water Infrastructure Lab, School of Civil, Mining and Environmental Engineering, University of Wollongong, Australia.

${ }^{\mathrm{b}}$ Molecular Biology Lab, School of Biological Sciences, University of Wollongong, Australia.

'Strategic Water Infrastructure Lab, School of Chemistry, University of Wollongong, Australia.

\footnotetext{
${ }^{*}$ Corresponding author: Faisal I. Hai (E-mail: faisal@uow.edu.au; Phone: +61-2-4221-3054)
} 


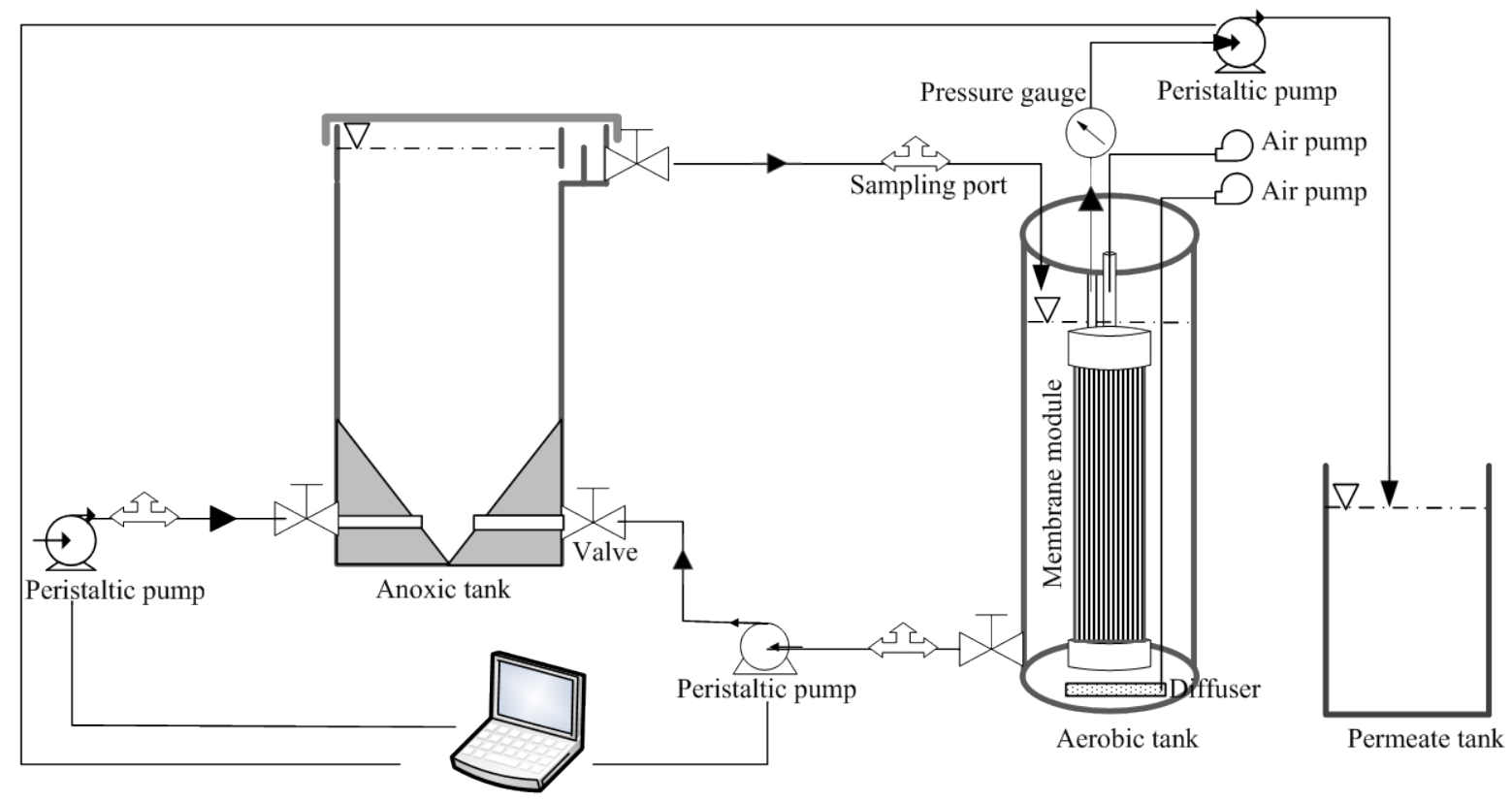

Figure S1: A schematic diagram of the laboratory scale anoxic-aerobic MBR. A hollow fiber ultrafiltration membrane module (Zeweed-10, Zenon Environmental, Canada) with nominal pore size of $0.04 \mu \mathrm{m}$ and membrane surface area of $0.93 \mathrm{~m}^{2}$ was submerged in aerobic reactor. Peristaltic pumps (Masterflex L/S, USA) were used for feeding, recirculation and effluent extraction. Effluent was extracted intermittently with a relaxation period of 2 min every $10 \mathrm{~min}$. Transmembrane pressure (TMP) was continuously recorded via a high resolution $( \pm 0.1 \mathrm{kPa})$ vacuum gauge. In situ air scrubbing was found adequate to keep the TMP stable below $5 \mathrm{kPa}$ without any chemical cleaning. The mixed liquor in upper quarter of the anoxic reactor was mixed intermittently (1 min on and 15 min off) by a mixer (200 rpm). 
Table S2: Physicochemical properties of the selected trace organic contaminants (TrOC).

\begin{tabular}{|c|c|c|c|c|c|}
\hline Category & Chemical formula & $\begin{array}{c}\text { Molecular weight } \\
(\mathrm{g} / \mathrm{mol})\end{array}$ & $\log D(\mathrm{pH} 8)^{\mathrm{a}}$ & $\begin{array}{l}\text { Henry's Law constant } \\
\text { at } 25^{\circ} \mathrm{C}\left(\mathrm{atm} \mathrm{m^{3 }} / \mathrm{mol}\right)^{\mathrm{a}}\end{array}$ & Molecular structure \\
\hline \multirow{7}{*}{$\begin{array}{c}\text { Pharmaceuticals and } \\
\text { personal care } \\
\text { products }\end{array}$} & $\begin{array}{c}\text { Diclofenac } \\
\left(\mathrm{C}_{14} \mathrm{H}_{11} \mathrm{Cl}_{2} \mathrm{NO}_{2}\right)\end{array}$ & 296.15 & 1.06 & $2.69 \times 10^{-11}$ & \\
\hline & $\begin{array}{l}\text { Carbamazepine } \\
\left(\mathrm{C}_{15} \mathrm{H}_{12} \mathrm{~N}_{2} \mathrm{O}\right)\end{array}$ & 236.27 & 1.89 & $9.41 \times 10^{-12}$ & \\
\hline & $\begin{array}{c}\text { Naproxen } \\
\left(\mathrm{C}_{14} \mathrm{H}_{14} \mathrm{O}_{3}\right)\end{array}$ & 230.30 & -0.18 & $6.08 \times 10^{-12}$ & \\
\hline & $\begin{array}{l}\text { Gemfibrozil } \\
\left(\mathrm{C}_{15} \mathrm{H}_{22} \mathrm{O}_{3}\right)\end{array}$ & 250.30 & 1.18 & $1.83 \times 10^{-11}$ & \\
\hline & $\begin{array}{c}\text { Primidone } \\
\left(\mathrm{C}_{12} \mathrm{H}_{14} \mathrm{~N}_{2} \mathrm{O}_{2}\right)\end{array}$ & 218.25 & 0.83 & $1.16 \times 10^{-14}$ & \\
\hline & $\begin{array}{l}\text { Ketoprofen } \\
\left(\mathrm{C}_{16} \mathrm{H}_{14} \mathrm{O}_{3}\right)\end{array}$ & 254.30 & -0.55 & $1.92 \times 10^{-13}$ & \\
\hline & $\begin{array}{c}\text { Metronidazole } \\
\left(\mathrm{C}_{6} \mathrm{H}_{9} \mathrm{~N}_{3} \mathrm{O}_{3}\right)\end{array}$ & 171.15 & -0.14 & $2.07 \times 10^{-12}$ & \\
\hline
\end{tabular}




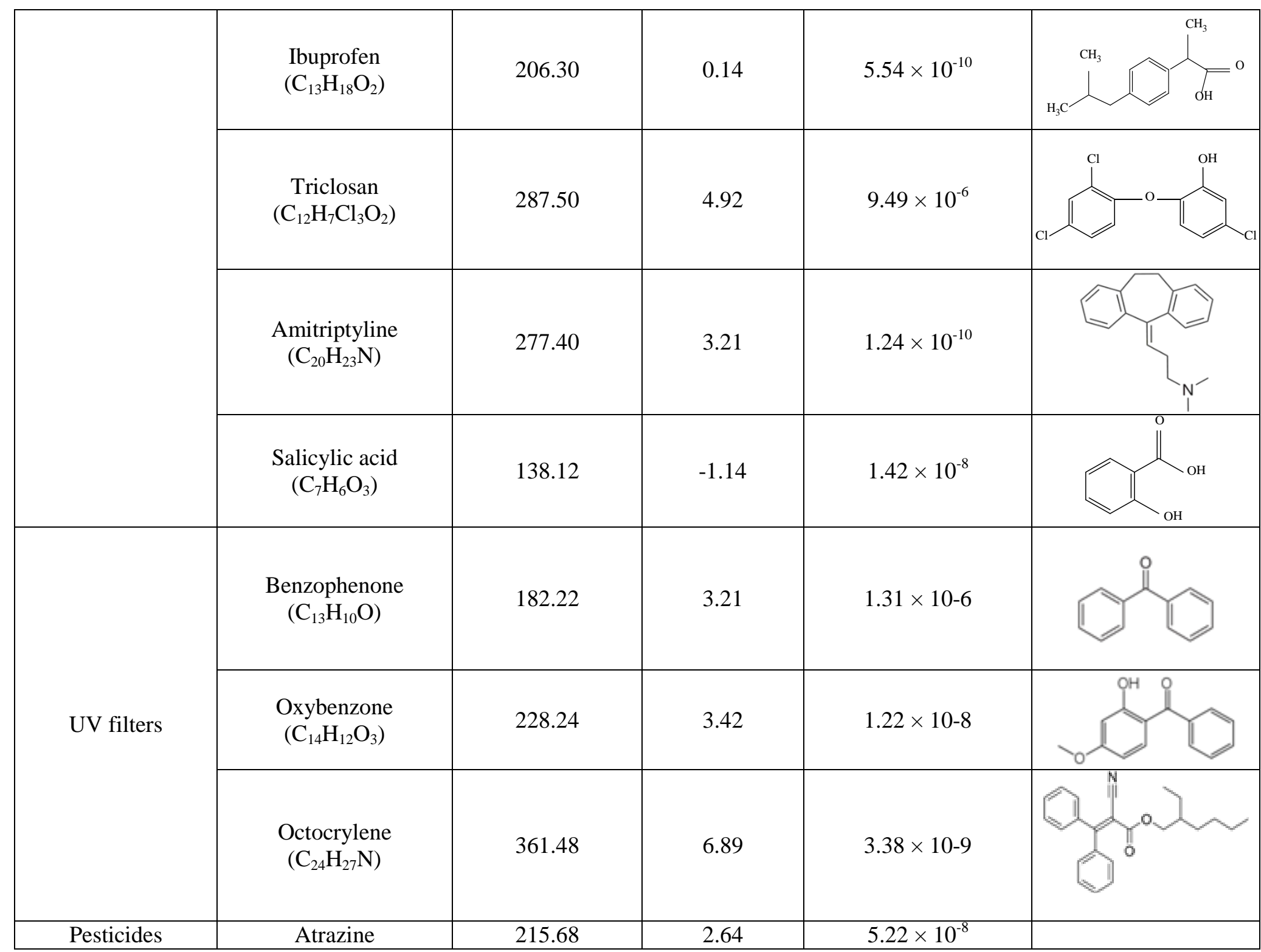




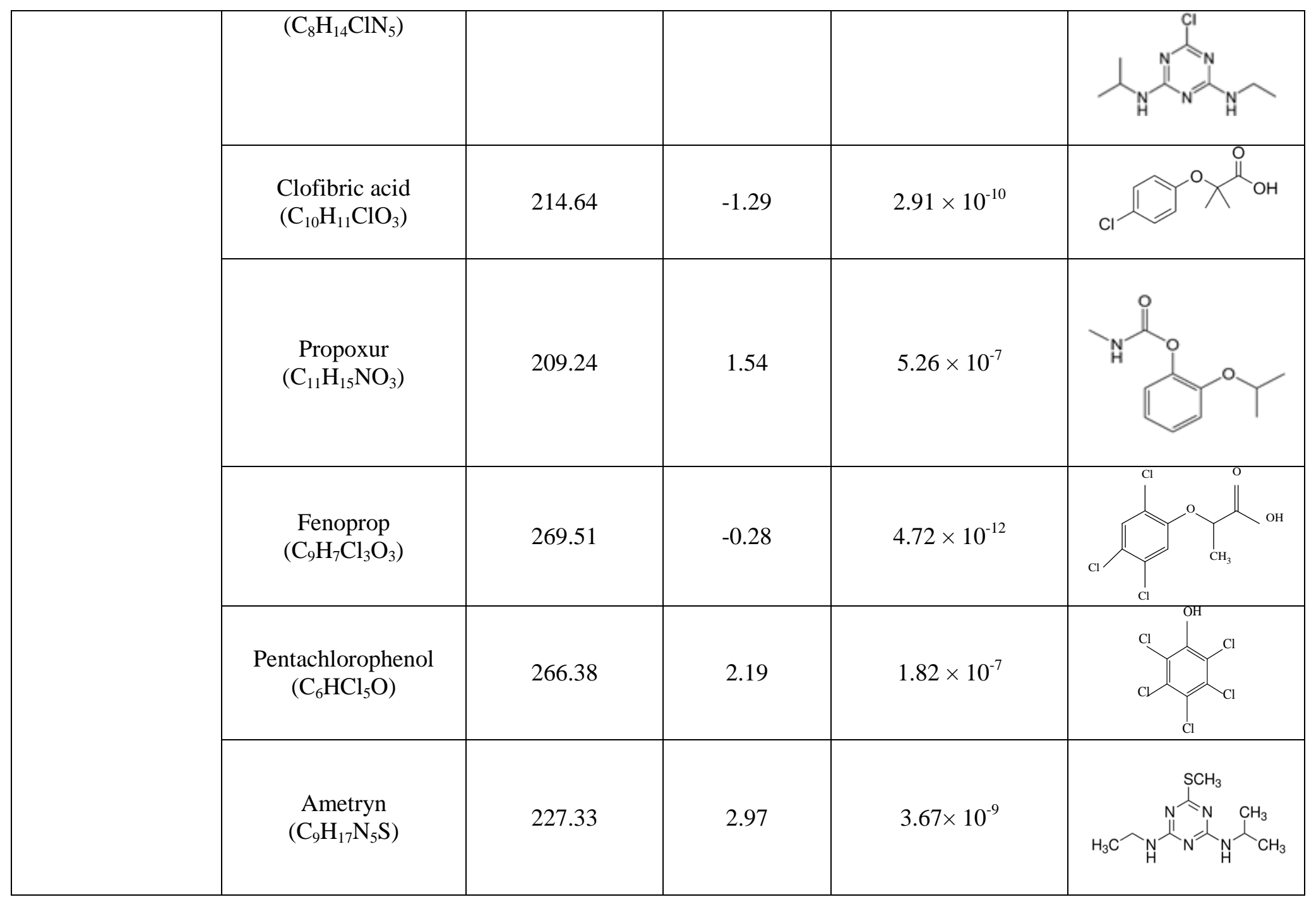




\begin{tabular}{|c|c|c|c|c|c|}
\hline \multirow{5}{*}{ Steroid hormones } & $\begin{array}{c}\text { 17a-Ethinylestradiol } \\
(\text { EE2) } \\
\left(\mathrm{C}_{20} \mathrm{H}_{24} \mathrm{O}_{2}\right)\end{array}$ & 296.48 & 4.11 & $3.74 \times 10^{-10}$ & \\
\hline & $\begin{array}{l}\text { Estriol (E3) } \\
\left(\mathrm{C}_{18} \mathrm{H}_{24} \mathrm{O}_{3}\right)\end{array}$ & 288.40 & 2.53 & $1.75 \times 10^{-11}$ & \\
\hline & $\begin{array}{l}\text { Estrone (E1) } \\
\left(\mathrm{C}_{18} \mathrm{H}_{22} \mathrm{O}_{2}\right)\end{array}$ & 270.36 & 3.62 & $9.61 \times 10^{-10}$ & \\
\hline & $\begin{array}{c}17 \beta \text {-Estradiol-17-acetate } \\
(\mathrm{E} 2 \mathrm{Ac}) \\
\left(\mathrm{C}_{20} \mathrm{H}_{26} \mathrm{O}_{3}\right)\end{array}$ & 314.42 & 5.11 & $2.15 \times 10^{-9}$ & \\
\hline & $\begin{array}{l}\text { 17ß-Estradiol (E2) } \\
\quad\left(\mathrm{C}_{18} \mathrm{H}_{24} \mathrm{O}_{2}\right)\end{array}$ & 272.38 & 4.14 & $1.17 \times 10^{-9}$ & \\
\hline \multirow{2}{*}{ Industrial chemicals } & $\begin{array}{l}\text { 4-tert-Butylphenol } \\
\left(\left(\mathrm{CH}_{3}\right)_{3} \mathrm{CC}_{6} \mathrm{H}_{4} \mathrm{OH}\right)\end{array}$ & 150.22 & 3.39 & $7.51 \times 10^{-6}$ & \\
\hline & $\begin{array}{l}\text { Bisphenol A } \\
\left(\mathrm{C}_{15} \mathrm{H}_{16} \mathrm{O}_{2}\right)\end{array}$ & 228.29 & 3.64 & $9.16 \times 10^{-12}$ & \\
\hline
\end{tabular}




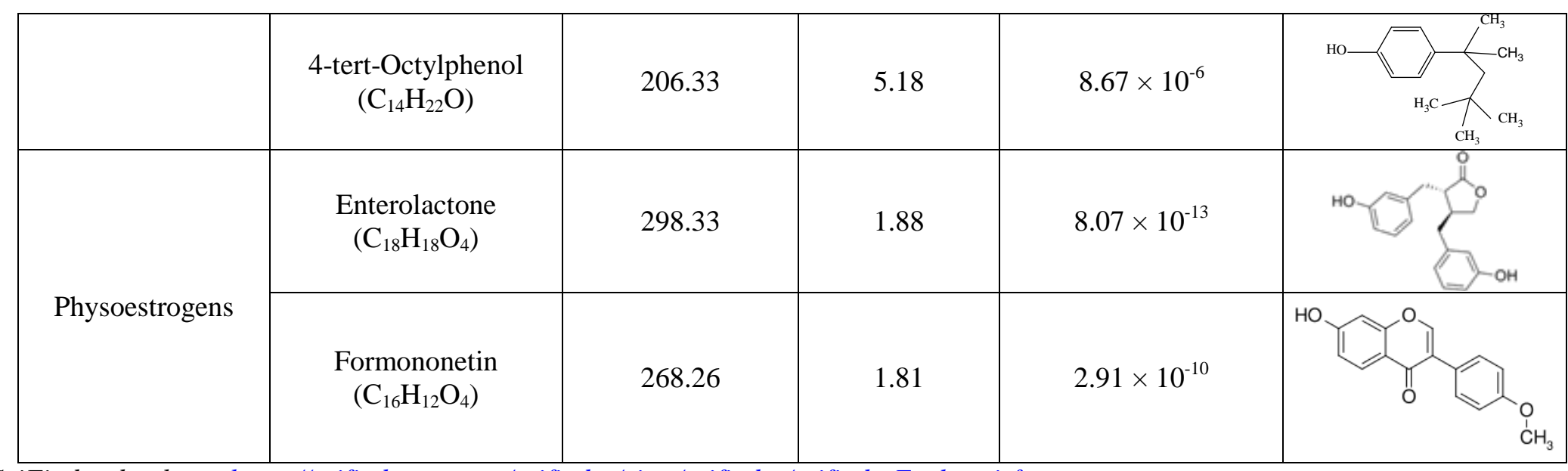

${ }^{a}$ Source: SciFinder database https://scifinder.cas.org/scifinder/view/scifinder/scifinderExplore.jsf

$\log D$ is logarithm of the distribution coefficient which is the ratio of the sum of concentrations of all forms of the compound (ionised and unionised) in octanol and waterat a given $\mathrm{pH}$. 
Table S3: TrOC removal (\%) by the anoxic reactor and the overall removal by the MBR (SRT = 25 d; values indicate average \pm standard deviation, $n=6$ ) (Phan et al., 2014)

\begin{tabular}{|l|c|c|c|c|}
\hline \multirow{2}{*}{ Compounds } & \multicolumn{2}{|c|}{ Anoxic reactor (\%) } & \multicolumn{2}{c|}{ Overall removal (\%) } \\
\cline { 2 - 5 } & IR $=3$ & IR $=0$ & IR $=3$ & IR $=0$ \\
\hline Diclofenac & $-23.5 \pm 25.4$ & $-89.0 \pm 12.3$ & $5.7 \pm 6.0$ & $-58.4 \pm 21.6$ \\
\hline Carbamazapine & $-23.9 \pm 60.8$ & $-0.8 \pm 18.1$ & $6.1 \pm 6.0$ & $17.7 \pm 11.7$ \\
\hline Naproxen & $18.1 \pm 13.3$ & $-12.8 \pm 6.1$ & $41.1 \pm 17.0$ & $79.4 \pm 4.5$ \\
\hline Gemfibrozil & $29.8 \pm 5.1$ & $-0.9 \pm 8.2$ & $47.8 \pm 5.5$ & $67.2 \pm 14.0$ \\
\hline Primidone & $71.2 \pm 12.5$ & $51.1 \pm 11.5$ & $55.0 \pm 16.4$ & $76.1 \pm 9.8$ \\
\hline Ketoprofen & $50.7 \pm 4.5$ & $5.5 \pm 7.2$ & $83.4 \pm 3.1$ & $86.3 \pm 4.6$ \\
\hline Metronidazole & $74.9 \pm 9.9$ & $76.7 \pm 18.8$ & $87.6 \pm 1.5$ & $87.9 \pm 6.3$ \\
\hline Ibuprofen & $69.4 \pm 3.1$ & $4.0 \pm 8.2$ & $93.3 \pm 1.4$ & $96.8 \pm 2.1$ \\
\hline Triclosan & $75.8 \pm 17.7$ & $65.7 \pm 6.0$ & $95.4 \pm 1.7$ & $97.2 \pm 0.2$ \\
\hline Amitriptyline & $85.6 \pm 3.2$ & $66.6 \pm 7.3$ & $97.6 \pm 1.1$ & $98.1 \pm 1.7$ \\
\hline Salicylic acid & $98.2 \pm 0.6$ & $17.0 \pm 10.1$ & $98.9 \pm 0.4$ & $98.9 \pm 0.4$ \\
\hline Benzophenone & $83.6 \pm 6.6$ & $55.4 \pm 9.5$ & $92.8 \pm 7.1$ & $99.6 \pm 0.8$ \\
\hline Oxybenzone & $87.4 \pm 4.7$ & $66.9 \pm 7.4$ & $93.1 \pm 2.1$ & $97.6 \pm 0.4$ \\
\hline Octocrylene & $86.5 \pm 21.7$ & $59.9 \pm 23.5$ & $95.5 \pm 3.8$ & $84.8 \pm 10.9$ \\
\hline Atrazine & $-42.8 \pm 21.0$ & $-56.2 \pm 28.9$ & $5.7 \pm 5.6$ & $-15.6 \pm 36.1$ \\
\hline Clofibric acid & $2.3 \pm 6.5$ & $0.5 \pm 6.0$ & $15.3 \pm 6.7$ & $9.5 \pm 5.5$ \\
\hline Propoxur & $8.9 \pm 10.2$ & $33.3 \pm 12.5$ & $17.1 \pm 10.4$ & $11.3 \pm 11.2$ \\
\hline Fenoprop & $3.1 \pm 13.8$ & $-21.8 \pm 26.2$ & $37.8 \pm 13.5$ & $31.3 \pm 13.0$ \\
\hline Pentachlorophenol & $54.2 \pm 4.3$ & $39.2 \pm 14.8$ & $58.8 \pm 5.4$ & $87.7 \pm 8.8$ \\
\hline Ametryn & $57.9 \pm 8.6$ & $-8.4 \pm 13.6$ & $84.0 \pm 6.8$ & $62.1 \pm 36.6$ \\
\hline $17 \alpha-E t h i n y l e s t r a d i o l$ & $76.5 \pm 4.8$ & $0.0 \pm 23.6$ & $92.5 \pm 2.2$ & $88.1 \pm 6.4$ \\
\hline Estriol & $82.7 \pm 2.6$ & $10.8 \pm 7.8$ & $97.5 \pm 2.0$ & $97.1 \pm 1.9$ \\
\hline Estrone & $70.4 \pm 7.4$ & $-5.1 \pm 15.0$ & $98.9 \pm 1.1$ & $99.1 \pm 0.6$ \\
\hline $17 \beta-E s t r a d i o l-17-a c e t a t e$ & $98.1 \pm 1.7$ & $82.5 \pm 9.5$ & $99.4 \pm 0.5$ & $99.3 \pm 0.5$ \\
\hline $17 \beta$-Estradiol & $95.2 \pm 0.7$ & $17.7 \pm 16.7$ & $99.9 \pm 0.1$ & $99.6 \pm 0.2$ \\
\hline 4 -tert-Butylphenol & $66.9 \pm 6.7$ & $40.3 \pm 16.1$ & $81.1 \pm 4.4$ & $84.5 \pm 3.2$ \\
\hline Bisphenol A & $66.2 \pm 5.6$ & $10.7 \pm 4.8$ & $85.4 \pm 2.5$ & $88.9 \pm 3.6$ \\
\hline $4-t e r t-O c t y l p h e n o l$ & $76.1 \pm 3.3$ & $67.3 \pm 13.6$ & $89.0 \pm 2.3$ & $84.6 \pm 8.0$ \\
\hline Enterolactone & $-7.8 \pm 43.6$ & $15.2 \pm 15.5$ & $64.7 \pm 16.3$ & $96.1 \pm 2.3$ \\
\hline Formononetin & $83.3 \pm 3.2$ & $23.9 \pm 13.1$ & $97.7 \pm 0.6$ & $98.0 \pm 2.0$ \\
\hline & & & & \\
\hline
\end{tabular}




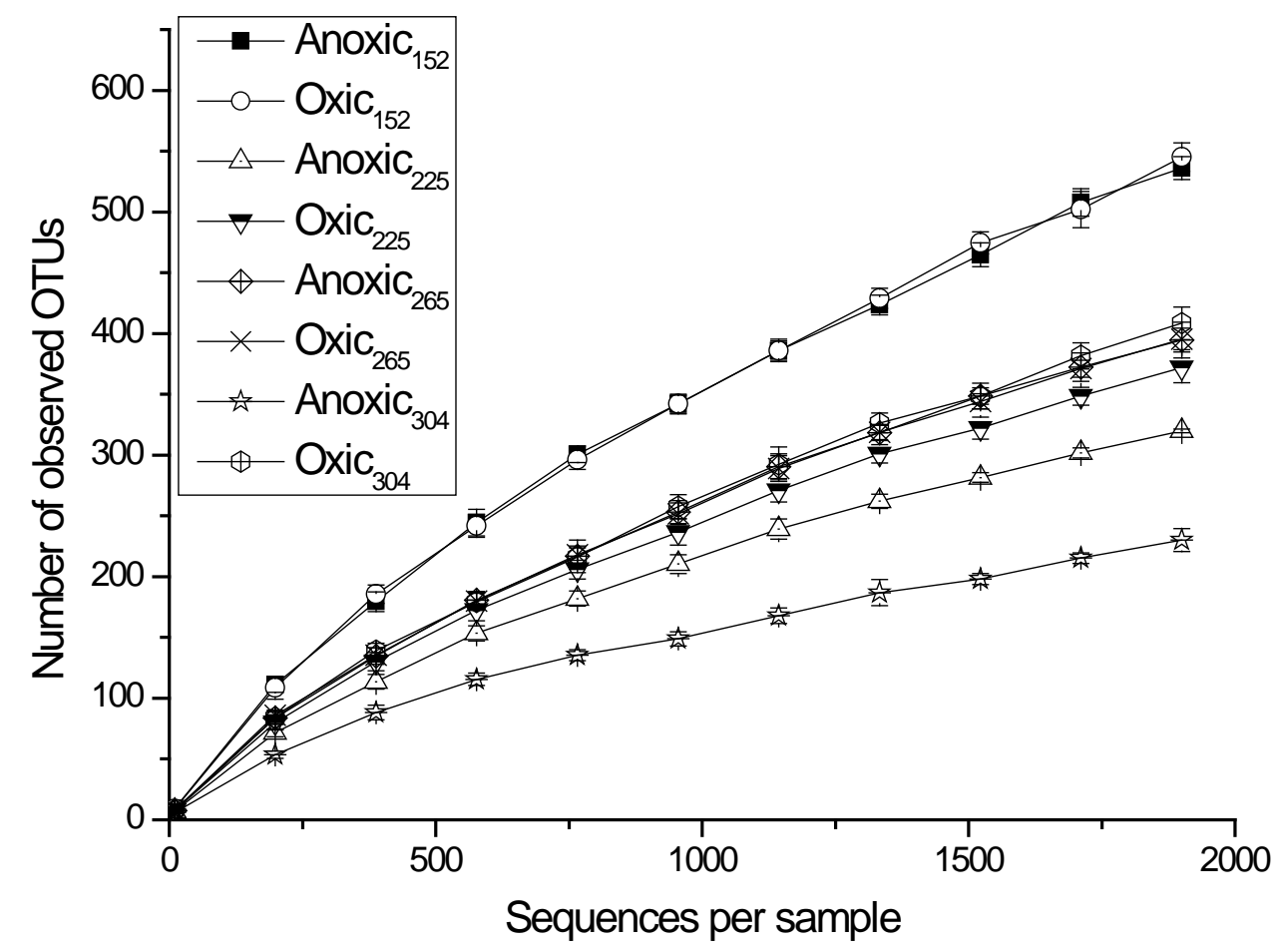

Figure S4: Rarefaction curves indicating the average observed number of operational taxonomic units (OTUs). Error bars indicate the standard deviation of 10 subsamples at a specified sequencing depth. $\alpha$-diversity indices were measured and compared at an even sequencing depth of 1900 sequences per sample. 
Table S5: Relative abundance (\%) of bacterial phyla. Anoxic and oxic samples were collected on day 152 (Condition 1: Infinite SRT, with TrOC, IR =3), day 225 (Condition 2: 25 d SRT, no TrOC, IR = 3), day 265 (Condition 3: 25 d SRT, with TrOC, IR = 3), and day 304 (Condition 4: 25 d SRT, with TrOCs, IR =0). 'Unclassified' indicates the sequences that could not be classified up to the phylum level.

\begin{tabular}{|l|c|c|c|c|c|c|c|c|}
\hline Taxon & Anoxic $_{152}$ & Oxic $_{152}$ & Anoxic $_{225}$ & Oxic $_{225}$ & Anoxic $_{265}$ & Oxic $_{265}$ & Anoxic $_{304}$ & Oxic $_{304}$ \\
\hline Unclassified & 10.53 & 10.90 & 14.90 & 12.52 & 9.63 & 7.77 & 4.44 & 14.96 \\
\hline Acidobacteria & 3.84 & 3.85 & 1.13 & 2.22 & 1.27 & 1.55 & 0.5 & 0.58 \\
\hline Actinobacteria & 0.65 & 0.23 & 0.31 & 0.47 & 0.69 & 0.85 & 0.03 & 0.84 \\
\hline Armatimonadetes & 1.61 & 3.13 & 0.67 & 0.53 & 0.28 & 0.13 & 0 & 0.02 \\
\hline BRC1 & 0 & 0 & 0.1 & 0 & 0 & 0 & 0 & 0 \\
\hline Bacteroidetes & 17.55 & 22.38 & 47.69 & 43.99 & 14.87 & 17.6 & 46.1 & 14.67 \\
\hline Chlorobi & 1.66 & 2.25 & 1.08 & 0.97 & 0.21 & 0.09 & 0.12 & 0.02 \\
\hline Chloroflexi & 5.46 & 5.93 & 0.36 & 0.62 & 2.21 & 2.59 & 0 & 0.02 \\
\hline Cyanobacteria & 0.23 & 0.21 & 0.1 & 0.19 & 0.11 & 0.13 & 0.03 & 0.23 \\
\hline Elusimicrobia & 0 & 0.08 & 0 & 0 & 0 & 0 & 0.03 & 0 \\
\hline Firmicutes & 0.38 & 0.41 & 0.41 & 0.37 & 0.86 & 1.39 & 3.61 & 0.39 \\
\hline GN02 & 0.02 & 0.02 & 0 & 0 & 0 & 0 & 0 & 0 \\
\hline Gemmatimonadetes & 0.7 & 0.99 & 0.36 & 0.12 & 0.09 & 0.06 & 0.03 & 0.04 \\
\hline Lentisphaerae & 0 & 0 & 0 & 0 & 0 & 0 & 0.77 & 0 \\
\hline NKB19 & 0.35 & 0.32 & 0 & 0.03 & 0.02 & 0.09 & 0 & 0 \\
\hline Nitrospirae & 3.11 & 2.44 & 0.57 & 0.66 & 0.21 & 0.7 & 0.89 & 0.7 \\
\hline OD1 & 0.65 & 0.71 & 0.26 & 0.31 & 0.52 & 0.41 & 1.45 & 0.33 \\
\hline OP11 & 0.02 & 0 & 0 & 0 & 0 & 0 & 0 & 0 \\
\hline Planctomycetes & 10.65 & 9.7 & 1.54 & 1.56 & 5.09 & 5.34 & 1.45 & 0.53 \\
\hline Proteobacteria & 40.57 & 34.76 & 22.76 & 26.1 & 60.06 & 57.57 & 39.14 & 64.11 \\
\hline Spirochaetes & 0.03 & 0 & 0.05 & 0.03 & 0 & 0 & 0.68 & 0 \\
\hline TM6 & 0 & 0 & 0 & 0 & 0.09 & 0.09 & 0.03 & 0.14 \\
\hline
\end{tabular}




\begin{tabular}{|l|c|c|c|c|c|c|c|c|} 
TM7 & 0.38 & 0.54 & 6.63 & 7.12 & 2.92 & 3.13 & 0.53 & 0 \\
\hline Thermotogae & 0 & 0 & 0 & 0 & 0 & 0 & 0 & 0.02 \\
\hline Verrucomicrobia & 1.45 & 0.86 & 0.82 & 1.65 & 0.54 & 0.28 & 0.15 & 2.33 \\
\hline WPS-2 & 0.16 & 0.28 & 0.26 & 0.53 & 0.34 & 0.22 & 0 & 0.11 \\
\hline [Thermi] & 0.02 & 0.02 & 0 & 0 & 0 & 0 & 0 & 0 \\
\hline
\end{tabular}

Table S6: Relative abundance (\%) of the bacterial phylotypes at the deepest level of classification (order, family or genus) revealed by the data analysed. Anoxic and oxic samples were collected on day 152 (Condition 1: Infinite SRT, with TrOC, IR = 3), 225 (Condition 2: 25 d SRT, no TrOC, IR = 3), 265 (Condition 3: 25d SRT, with TrOC, IR = 3), and 304 (Condition 4: 25 d SRT, with TrOC, IR = 0). The bacterial phylotypes that were observed at less than $0.45 \%$ average abundance were grouped in 'Others'. The protocol used in this study could provide information up to the genus level, but in some cases analysed data fell short to reveal the genus ("g__"), family ("f__”), order (“o_””) or even the class (c__).

\begin{tabular}{|c|c|c|c|c|c|c|c|c|}
\hline Consensus lineage (Phylum;Class;Order;Family;Genus) & Anoxic $_{152}$ & Oxic $_{152}$ & Anoxic $_{225}$ & Oxic $_{225}$ & Anoxic $_{265}$ & Oxic $_{265}$ & Anoxic $_{304}$ & Oxic $_{304}$ \\
\hline Acidobacteria;Holophagae;Holophagales;Holophagaceae;g_ & 0.23 & 0.47 & 0.21 & 0.19 & 0.04 & 0.09 & 0.41 & 0.23 \\
\hline Acidobacteria;[Chloracidobacteria];PK29;f__g_ & 0.59 & 0.53 & 0.05 & 0.06 & 0.15 & 0.00 & 0.00 & 0.02 \\
\hline Acidobacteria;[Chloracidobacteria];RB41;Ellin6075;g__ & 2.04 & 2.03 & 0.57 & 1.62 & 0.82 & 1.33 & 0.03 & 0.00 \\
\hline $\begin{array}{l}\text { Armatimonadetes;[Fimbriimonadia];[Fimbriimonadales]; } \\
\text { [Fimbriimonadaceae];g__ }\end{array}$ & 0.91 & 0.86 & 0.51 & 0.44 & 0.24 & 0.13 & 0.00 & 0.00 \\
\hline $\begin{array}{l}\text { Armatimonadetes;[Fimbriimonadia];[Fimbriimonadales]; } \\
\text { [Fimbriimonadaceae];Fimbriimonas }\end{array}$ & 0.68 & 2.01 & 0.15 & 0.09 & 0.04 & 0.00 & 0.00 & 0.00 \\
\hline $\begin{array}{l}\text { Bacteroidetes;Bacteroidia;Bacteroidales;Bacteroidaceae; } \\
\text { Bacteroides }\end{array}$ & 0.00 & 0.00 & 0.00 & 0.00 & 0.00 & 0.00 & 0.50 & 0.02 \\
\hline Bacteroidetes;Cytophagia;Cytophagales;f_;g__ & 1.15 & 1.89 & 0.00 & 0.06 & 0.00 & 0.03 & 0.03 & 0.74 \\
\hline Bacteroidetes;Cytophagia;Cytophagales;Cytophagaceae;g_ & 8.24 & 12.40 & 35.20 & 29.44 & 6.92 & 8.94 & 37.63 & 7.04 \\
\hline Bacteroidetes;Cytophagia;Cytophagales;Cytophagaceae;Runella & 0.79 & 1.13 & 0.67 & 0.19 & 0.17 & 0.22 & 0.00 & 0.49 \\
\hline $\begin{array}{l}\text { Bacteroidetes;Flavobacteriia;Flavobacteriales; } \\
\text { Cryomorphaceae;g_ }\end{array}$ & 2.60 & 2.36 & 5.86 & 5.78 & 0.41 & 0.35 & 0.24 & 0.16 \\
\hline
\end{tabular}




\begin{tabular}{|c|c|c|c|c|c|c|c|c|}
\hline $\begin{array}{l}\text { Bacteroidetes;Flavobacteriia;Flavobacteriales;Flavobacteriaceae; } \\
\text { Flavobacterium }\end{array}$ & 0.00 & 0.00 & 0.00 & 0.06 & 0.00 & 0.00 & 0.00 & 3.75 \\
\hline $\begin{array}{l}\text { Bacteroidetes;Flavobacteriia;Flavobacteriales;[Weeksellaceae]; } \\
\text { Chryseobacterium }\end{array}$ & 1.00 & 0.51 & 0.21 & 0.44 & 0.04 & 0.00 & 3.08 & 0.02 \\
\hline Bacteroidetes;Sphingobacteriia;Sphingobacteriales;f__;g__ & 0.31 & 0.47 & 0.31 & 0.09 & 0.30 & 0.41 & 0.09 & 0.68 \\
\hline Bacteroidetes;[Saprospirae];[Saprospirales];f__g__ & 3.11 & 2.96 & 0.00 & 0.25 & 0.00 & 0.13 & 0.24 & 0.12 \\
\hline Bacteroidetes;[Saprospirae];[Saprospirales];Chitinophagaceae;g__ & 0.30 & 0.53 & 5.09 & 6.43 & 5.69 & 5.15 & 2.90 & 1.45 \\
\hline Bacteroidetes;[Saprospirae];[Saprospirales];Saprospiraceae;g & 0.02 & 0.04 & 0.26 & 1.12 & 1.33 & 2.37 & 0.36 & 0.14 \\
\hline Chlorobi;SJA-28;o__f__;g__ & 1.20 & 1.82 & 0.87 & 0.75 & 0.21 & 0.09 & 0.06 & 0.00 \\
\hline $\begin{array}{l}\text { Chloroflexi;Anaerolineae;Anaerolineales;Anaerolinaceae; } \\
\text { Longilinea }\end{array}$ & 1.33 & 1.52 & 0.00 & 0.00 & 0.09 & 0.00 & 0.00 & 0.00 \\
\hline Chloroflexi;Anaerolineae;Caldilineales;Caldilineaceae;Caldilinea & 0.09 & 0.02 & 0.10 & 0.19 & 1.31 & 1.39 & 0.00 & 0.00 \\
\hline Chloroflexi;Anaerolineae;SBR1031;f__A4b;g_ & 1.03 & 1.61 & 0.05 & 0.28 & 0.00 & 0.00 & 0.00 & 0.00 \\
\hline Chloroflexi;Anaerolineae;SHA-20;f__g__ & 0.40 & 0.23 & 0.05 & 0.12 & 0.52 & 0.73 & 0.00 & 0.00 \\
\hline Chloroflexi;Anaerolineae;envOPS12;f__g__ & 1.17 & 1.28 & 0.10 & 0.00 & 0.02 & 0.06 & 0.00 & 0.00 \\
\hline Firmicutes;Bacilli;Lactobacillales;Streptococcaceae;Lactococcus & 0.14 & 0.23 & 0.10 & 0.16 & 0.56 & 1.20 & 0.03 & 0.02 \\
\hline Firmicutes;Clostridia;Clostridiales;Veillonellaceae;Anaeromusa & 0.00 & 0.00 & 0.00 & 0.00 & 0.11 & 0.00 & 0.68 & 0.02 \\
\hline $\begin{array}{l}\text { Firmicutes;Clostridia;Clostridiales;[Acidaminobacteraceae]; } \\
\text { Fusibacter }\end{array}$ & 0.16 & 0.06 & 0.05 & 0.00 & 0.00 & 0.00 & 2.01 & 0.02 \\
\hline Gemmatimonadetes;Gemmatimonadetes;o__f__;g__ & 0.42 & 0.56 & 0.05 & 0.06 & 0.02 & 0.03 & 0.03 & 0.04 \\
\hline Lentisphaerae;[Lentisphaeria];Victivallales;Victivallaceae;g__ & 0.00 & 0.00 & 0.00 & 0.00 & 0.00 & 0.00 & 0.77 & 0.00 \\
\hline Nitrospirae;Nitrospira;Nitrospirales;Nitrospiraceae;Nitrospira & 3.07 & 2.44 & 0.57 & 0.66 & 0.21 & 0.70 & 0.89 & 0.70 \\
\hline OD1;SM2F11;0__f__; _ & 0.30 & 0.45 & 0.10 & 0.16 & 0.52 & 0.41 & 1.21 & 0.19 \\
\hline Planctomycetes;Phycisphaerae;Phycisphaerales;f__g__ & 5.08 & 5.42 & 0.92 & 0.75 & 0.54 & 1.36 & 0.74 & 0.12 \\
\hline Planctomycetes;Planctomycetia;Gemmatales;Gemmataceae;g_ & 1.62 & 1.35 & 0.36 & 0.19 & 1.74 & 1.77 & 0.12 & 0.18 \\
\hline $\begin{array}{l}\text { Planctomycetes;Planctomycetia;Gemmatales;Gemmataceae; } \\
\text { Gemmata }\end{array}$ & 0.63 & 0.38 & 0.10 & 0.03 & 0.32 & 0.28 & 0.00 & 0.04 \\
\hline Planctomycetes;Planctomycetia;Pirellulales;Pirellulaceae;g__ & 0.87 & 0.56 & 0.05 & 0.16 & 0.49 & 0.47 & 0.06 & 0.00 \\
\hline $\begin{array}{l}\text { Planctomycetes;Planctomycetia;Planctomycetales; } \\
\text { Planctomycetaceae;Planctomyces }\end{array}$ & 2.08 & 1.74 & 0.05 & 0.09 & 1.85 & 1.33 & 0.30 & 0.02 \\
\hline Proteobacteria;Alphaproteobacteria;o__;f__g__ & 0.26 & 0.60 & 0.00 & 0.22 & 0.11 & 0.03 & 0.92 & 0.68 \\
\hline
\end{tabular}




\begin{tabular}{|c|c|c|c|c|c|c|c|c|}
\hline Proteobacteria;Alphaproteobacteria;o__Rhizobiales;f__g__ & 0.59 & 1.16 & 0.62 & 0.59 & 0.47 & 0.54 & 0.06 & 2.28 \\
\hline $\begin{array}{l}\text { Proteobacteria;Alphaproteobacteria;Rhizobiales; } \\
\text { Hyphomicrobiaceae;Hyphomicrobium }\end{array}$ & 0.14 & 0.15 & 0.00 & 0.06 & 0.45 & 0.60 & 0.12 & 0.23 \\
\hline $\begin{array}{l}\text { Proteobacteria;Alphaproteobacteria;Rhizobiales; } \\
\text { Methylocystaceae;Methylosinus }\end{array}$ & 0.00 & 0.00 & 0.00 & 0.00 & 0.37 & 0.85 & 0.00 & 0.04 \\
\hline $\begin{array}{l}\text { Proteobacteria;Alphaproteobacteria;Rhizobiales; } \\
\text { Phyllobacteriaceae;g__ }\end{array}$ & 0.09 & 0.13 & 0.10 & 0.16 & 0.54 & 0.28 & 0.00 & 0.04 \\
\hline $\begin{array}{l}\text { Proteobacteria;Alphaproteobacteria;Rhodobacterales; } \\
\text { Hyphomonadaceae;g }\end{array}$ & 0.86 & 0.54 & 0.05 & 0.34 & 0.11 & 0.13 & 0.00 & 1.68 \\
\hline Proteobacteria;Alphaproteobacteria;Rhodospirillales;f__;g__ & 0.07 & 0.06 & 0.05 & 0.06 & 0.45 & 0.09 & 0.09 & 0.28 \\
\hline $\begin{array}{l}\text { Proteobacteria;Alphaproteobacteria;Rhodospirillales; } \\
\text { Acetobacteraceae;g__ }\end{array}$ & 0.14 & 0.04 & 0.10 & 0.22 & 0.19 & 0.13 & 0.65 & 0.04 \\
\hline $\begin{array}{l}\text { Proteobacteria;Alphaproteobacteria;Rhodospirillales; } \\
\text { Rhodospirillaceae;g }\end{array}$ & 0.72 & 0.62 & 0.41 & 0.56 & 1.14 & 1.04 & 0.36 & 0.89 \\
\hline $\begin{array}{l}\text { Proteobacteria;Betaproteobacteria;Burkholderiales; } \\
\text { Other;Other }\end{array}$ & 0.02 & 0.04 & 0.05 & 0.06 & 0.09 & 0.06 & 0.03 & 0.96 \\
\hline $\begin{array}{l}\text { Proteobacteria;Betaproteobacteria;Burkholderiales; } \\
\text { Alcaligenaceae;g__ }\end{array}$ & 0.02 & 0.00 & 0.46 & 0.06 & 0.13 & 0.06 & 0.39 & 0.47 \\
\hline $\begin{array}{l}\text { Proteobacteria;Betaproteobacteria;Burkholderiales; } \\
\text { Comamonadaceae;g }\end{array}$ & 1.47 & 1.05 & 0.72 & 0.81 & 0.30 & 0.35 & 0.83 & 4.90 \\
\hline $\begin{array}{l}\text { Proteobacteria;Betaproteobacteria;Burkholderiales; } \\
\text { Comamonadaceae;Comamonas }\end{array}$ & 0.21 & 0.08 & 0.10 & 0.00 & 0.02 & 0.00 & 0.65 & 0.04 \\
\hline $\begin{array}{l}\text { Proteobacteria;Betaproteobacteria;Burkholderiales; } \\
\text { Comamonadaceae;Methylibium }\end{array}$ & 0.09 & 0.06 & 0.00 & 0.12 & 0.09 & 0.03 & 0.06 & 0.47 \\
\hline $\begin{array}{l}\text { Proteobacteria;Betaproteobacteria;Burkholderiales; } \\
\text { Oxalobacteraceae;g__ }\end{array}$ & 2.30 & 2.34 & 0.92 & 0.62 & 0.77 & 1.04 & 0.21 & 0.75 \\
\hline Proteobacteria;Betaproteobacteria;Ellin6067;f_;g_ & 1.47 & 0.83 & 0.62 & 0.87 & 0.62 & 0.95 & 0.21 & 0.04 \\
\hline $\begin{array}{l}\text { Proteobacteria;Betaproteobacteria;Methylophilales; } \\
\text { Methylophilaceae;g__ }\end{array}$ & 3.91 & 2.78 & 0.00 & 0.00 & 31.05 & 27.87 & 3.79 & 6.04 \\
\hline $\begin{array}{l}\text { Proteobacteria;Betaproteobacteria;Methylophilales; } \\
\text { Methylophilaceae;Methylotenera }\end{array}$ & 0.31 & 0.34 & 0.00 & 0.00 & 1.46 & 1.55 & 0.15 & 0.60 \\
\hline $\begin{array}{l}\text { Proteobacteria;Betaproteobacteria;Neisseriales; } \\
\text { Neisseriaceae;g__Aquitalea }\end{array}$ & 0.75 & 0.23 & 0.00 & 0.00 & 0.00 & 0.00 & 0.12 & 0.00 \\
\hline Proteobacteria;Betaproteobacteria;Rhodocyclales; & 0.56 & 0.77 & 0.72 & 0.59 & 0.37 & 0.70 & 0.15 & 0.82 \\
\hline
\end{tabular}




\begin{tabular}{|c|c|c|c|c|c|c|c|c|}
\hline Rhodocyclaceae;Other & & & & & & & & \\
\hline $\begin{array}{l}\text { Proteobacteria;Betaproteobacteria;Rhodocyclales; } \\
\text { Rhodocyclaceae;g__ }\end{array}$ & 8.36 & 6.27 & 1.59 & 2.44 & 3.67 & 3.32 & 1.66 & 2.49 \\
\hline $\begin{array}{l}\text { Proteobacteria;Betaproteobacteria;Rhodocyclales; } \\
\text { Rhodocyclaceae;Azospira }\end{array}$ & 0.00 & 0.00 & 0.10 & 0.00 & 0.00 & 0.00 & 1.16 & 0.14 \\
\hline $\begin{array}{l}\text { Proteobacteria;Betaproteobacteria; Rhodocyclales; } \\
\text { Rhodocyclaceae;Candidatus Accumulibacter }\end{array}$ & 1.87 & 1.91 & 5.19 & 5.40 & 5.87 & 6.89 & 0.39 & 0.07 \\
\hline $\begin{array}{l}\text { Proteobacteria;Betaproteobacteria; Rhodocyclales; } \\
\text { Rhodocyclaceae;Dechloromonas }\end{array}$ & 0.89 & 2.01 & 0.92 & 1.47 & 0.71 & 0.57 & 1.04 & 0.14 \\
\hline $\begin{array}{l}\text { Proteobacteria;Betaproteobacteria;Methylophilales; } \\
\text { Methylophilaceae;Other }\end{array}$ & 0.00 & 0.00 & 0.00 & 0.00 & 0.43 & 0.54 & 0.15 & 0.18 \\
\hline $\begin{array}{l}\text { Proteobacteria;Betaproteobacteria;Rhodocyclales; } \\
\text { Rhodocyclaceae;Methyloversatilis }\end{array}$ & 0.79 & 0.53 & 0.00 & 0.00 & 0.09 & 0.06 & 0.06 & 0.04 \\
\hline Proteobacteria;Betaproteobacteria;SC-I-84;f__g_- & 0.80 & 0.51 & 0.21 & 0.09 & 0.52 & 0.47 & 0.27 & 0.00 \\
\hline $\begin{array}{l}\text { Proteobacteria;Deltaproteobacteria;Bdellovibrionales; } \\
\text { Bdellovibrionaceae;Bdellovibrio }\end{array}$ & 0.56 & 0.90 & 0.31 & 0.47 & 0.15 & 0.03 & 0.00 & 0.49 \\
\hline Proteobacteria;Deltaproteobacteria;Myxococcales;f__g__ & 6.08 & 4.75 & 5.04 & 4.65 & 5.07 & 4.61 & 0.24 & 32.17 \\
\hline $\begin{array}{l}\text { Proteobacteria;Deltaproteobacteria;Myxococcales; } \\
\text { 0319-6G20;g__ }\end{array}$ & 0.02 & 0.04 & 0.05 & 0.03 & 0.00 & 0.03 & 0.00 & 0.82 \\
\hline $\begin{array}{l}\text { Proteobacteria;Deltaproteobacteria;Myxococcales; } \\
\text { Nannocystaceae;Nannocystis }\end{array}$ & 0.94 & 0.69 & 0.21 & 0.12 & 0.19 & 0.06 & 0.00 & 0.32 \\
\hline $\begin{array}{l}\text { Proteobacteria;Gammaproteobacteria;Chromatiales; } \\
\text { Chromatiaceae;Allochromatium }\end{array}$ & 0.09 & 0.34 & 0.05 & 0.00 & 0.11 & 0.47 & 0.00 & 0.00 \\
\hline $\begin{array}{l}\text { Proteobacteria;Gammaproteobacteria;Enterobacteriales; } \\
\text { Enterobacteriaceae;g__ }\end{array}$ & 0.26 & 0.19 & 0.41 & 0.09 & 0.17 & 0.16 & 12.50 & 0.42 \\
\hline Proteobacteria;Gammaproteobacteria;HOC36;f__;__ & 0.47 & 0.09 & 0.00 & 0.06 & 0.21 & 0.38 & 0.00 & 0.00 \\
\hline $\begin{array}{l}\text { Proteobacteria;Gammaproteobacteria;Pseudomonadales; } \\
\text { Moraxellaceae;Acinetobacter }\end{array}$ & 0.94 & 1.33 & 2.42 & 3.25 & 2.06 & 1.80 & 12.00 & 2.19 \\
\hline $\begin{array}{l}\text { Proteobacteria;Gammaproteobacteria;Xanthomonadales; } \\
\text { Sinobacteraceae;g__ }\end{array}$ & 0.89 & 0.41 & 0.15 & 0.72 & 0.28 & 0.16 & 0.09 & 0.51 \\
\hline $\begin{array}{l}\text { Spirochaetes;Spirochaetes;Spirochaetales;Spirochaetaceae; } \\
\text { Treponema }\end{array}$ & 0.03 & 0.00 & 0.05 & 0.03 & 0.00 & 0.00 & 0.68 & 0.00 \\
\hline TM7;TM7-1;o_;f_;g_ & 0.26 & 0.47 & 6.63 & 7.12 & 2.92 & 3.13 & 0.09 & 0.00 \\
\hline
\end{tabular}




\begin{tabular}{|c|c|c|c|c|c|c|c|c|}
\hline TM7;TM7-3;Blgi18;f__g__ & 0.00 & 0.00 & 0.00 & 0.00 & 0.00 & 0.00 & 0.44 & 0.00 \\
\hline Verrucomicrobia;Opitutae;Opitutales;Opitutaceae;g__ & 0.59 & 0.30 & 0.00 & 0.06 & 0.00 & 0.00 & 0.00 & 0.00 \\
\hline Verrucomicrobia;[Pedosphaerae];[Pedosphaerales];f__g_ & 0.30 & 0.15 & 0.36 & 0.37 & 0.00 & 0.03 & 0.12 & 1.94 \\
\hline Verrucomicrobia;[Pedosphaerae];[Pedosphaerales];Ellin515;g__ & 0.14 & 0.13 & 0.15 & 0.56 & 0.00 & 0.06 & 0.03 & 0.05 \\
\hline WPS-2;c_;o__f__;g__ & 0.16 & 0.28 & 0.26 & 0.53 & 0.34 & 0.22 & 0.00 & 0.11 \\
\hline Others & 9.29 & 8.05 & 3.13 & 4.37 & 3.93 & 3.63 & 2.76 & 5.06 \\
\hline Unclassified at phylum level & 10.53 & 10.90 & 14.90 & 12.52 & 9.63 & 7.77 & 4.44 & 14.96 \\
\hline
\end{tabular}

